
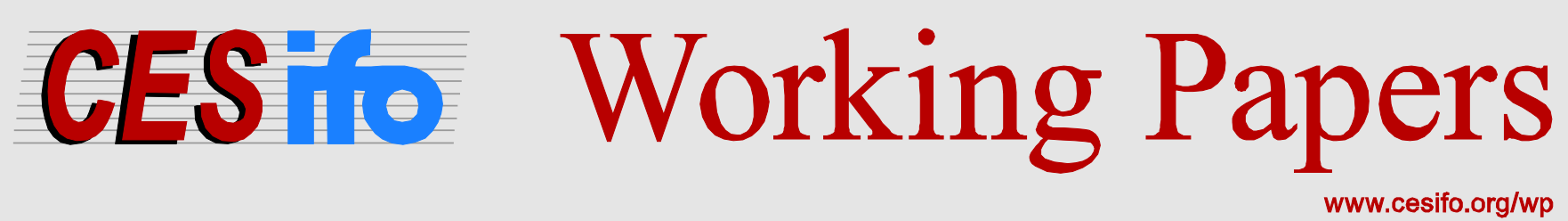

\title{
Centralized Fiscal Spending by Supranational Unions
}

\author{
Jenny Simon \\ Justin M. Valasek
}

CESIFO WORKING PAPER NO. 4321

CATEgORY 1: PuBliC FINANCE

JULY 2013

An electronic version of the paper may be downloaded

- from the SSRN website:

- from the RePEc website:

- from the CESifo website:

WWW.SSRN.com

www.RePEc.org

www.CESifo-group.org/wp

\section{CESifo}




\title{
Centralized Fiscal Spending by Supranational Unions
}

\begin{abstract}
We study fiscal spending by supranational unions, where participation is voluntary and countries bargain over contributions to and the allocation of a central budget. We explore the link between the allocation and nations' contributions that occurs since bargaining power is endogenous, and generically causes inefficiency. Interestingly, redistribution arises endogenously, despite nations being purely self-interested. However, there exists a trade-off between increasing equality and decreasing efficiency, which becomes more severe as the centralized budget increases. We also analyze partial ex-ante commitment through alternative decision-making institutions: Both majority rule and exogenous tax rules can improve efficiency.
\end{abstract}

JEL-Code: H770, H870, D710.

Keywords: supranational unions, efficiency, public goods, redistribution, federalism, legislative bargaining.

\author{
Jenny Simon \\ Stockholm Institute of Transition \\ Economics \\ Sveavägen 65 \\ Sweden-11383 Stockholm \\ jenny.simon@hhs.se
}

\author{
Justin M. Valasek \\ Social Science Research Center Berlin \\ (WZB) / Market and Politics Research Unit \\ Reichpietschufer 50 \\ Germany-10785 Berlin \\ justin.valasek@wzb.eu
}

First version: June 20, 2012

This version: June 28, 2013

We are thankful for helpful discussions with Bård Harstad, Steffen Huck, Macartan Humphreys, Kai Konrad, Rachel Kranton, Ben Lockwood, Ramon Marimon, Andrea Mattozzi, Gérard Roland, Fernando Vega-Redondo, and Ivan Werning, as well as conference and seminar participants at SED 2012, the "End of Federalism?" Conference, the WZB and SITE. All errors are our own. 


\section{Motivation}

Increasing regional integration bears testimony to potentially large gains from coordinating policy at the supranational level. However, centralized fiscal spending is rare, even among groups of nations that coordinate on many policy areas: For example, in the most integrated regional body, the European Union, fiscal spending remains small and there exists an overwhelming perception that the available funds are inefficiently allocated. ${ }^{1}$ This is surprising given the fiscal federalism literature's classic predictions of efficiency gains from coordinated public goods provision. ${ }^{2}$ What prevents groups of sovereign nations from effectively conducting the basic fiscal task of raising and allocating a budget? This question is of broad interest for aspiring unions such as the East African Community and the Union of South American Nations, supranational organizations, and current proposals to expand centralized fiscal spending in the EU.

In this paper, we show how the voluntary nature of supranational governance prevents the efficient provision of centralized spending, at least in the presence of income asymmetry between member nations. In stark contrast to a federation, sovereign nations cannot commit to remain in the union. Because of this, contributions to the union budget influence the de facto distribution of bargaining power over the allocation of the budget - a link that generally leads to inefficient outcomes.

More specifically, we provide a theoretical framework to analyze how bargaining affects centralized fiscal spending when self-interested nations voluntarily participate in a union and cannot commit ex-ante to binding contracts over contributions to the central budget and the allocation of the joint funds. ${ }^{3}$ In our model, the motivation to form a union stems from a set of projects that benefit from centralized provision, modeled as a technology unavailable to each nation individually. Nations have heterogeneous preferences over these projects, but enjoy positive spillovers from all of them. As an example, one may think about joint resources being spent on infrastructure improvement: Every member country likely gains from an integrated transportation network; at the same time each country might prefer, all else equal, that spending is allocated to infrastructure projects within its borders.

To analyze how sovereign countries agree on contributions to the union budget as well as its allocation to union projects, a natural modeling choice is unstructured bargaining. ${ }^{4}$ Our paper shows that in a supranational setting, the distribution of

\footnotetext{
${ }^{1}$ See Dellmuth and Stoffel (2012) for a review.

${ }^{2}$ That is, there are net efficiency gains from centralization in at least some policy areas; see for example Oates (1972), pp. 4-11 and the more recent contributions of Lockwood (2002) and Besley and Coate (2003) for a discussion.

${ }^{3}$ This modeling feature pertains to the EU, as recently highlighted by the UK's threat to veto the entire EU budget. As Carrubba (1997) argues, contributions to the centralized budget are flexible and subject to bargaining given that "the member states maintain ex-post control over every country's net transfer position" (p. 473).

${ }^{4}$ Current EU centralized fiscal spending is largely comprised of the structural and cohesion funds, and both budget and allocation decisions for these funds are negotiated by national representatives behind closed doors - a process most closely approximated by the Nash bargaining mechanism
} 
bargaining power implicit in the Nash bargaining solution arises endogenously from the countries' contributions, their national incomes, and the public good spillovers of their preferred projects: this is our main departure from the existing literature.

We highlight the resulting link between contributions and allocations through the implied bargaining position as a major source of inefficiency in a union's spending decision. The intuition for this link is best explained in a "partial equilibrium" thought experiment: Suppose contributions to the union budget are fixed before nations bargaining over the allocation of the joint funds. Each nation's bargaining position depends on its outside option, which is to withdraw from the union and consume its contribution. Therefore, a higher contribution, all else equal, implies a larger outside option, and a stronger position to bargain for the individually preferred (but possibly inefficient) allocation of funds. Thus, the allocation of the union budget to union projects is linked to the scheme of individual contributions. That is not the case in the efficient allocation, where funds should simply be allocated to the highest marginal return projects, without regard to who finances the joint budget. This link is a direct consequence of the voluntary nature of supranational spending - it would not be present if nations could not threaten to withdraw their contribution and revert to autarky during the bargaining process. We show that this source of inefficiency is retained in the "general equilibrium" setup, where nations bargain simultaneously over contributions and the allocation. This interdependency of contributions and allocation of funds generically results in distortions both in terms of efficient funding as well as efficient spending.

Our setup allows us to explicitly track under which circumstances unstructured bargaining leads to inefficient outcomes. Surprisingly, in some cases it does actually achieve efficiency: First, when nations are symmetric with regard to income, and all projects have the same level of spillovers, then the budget is raised and allocated efficiently. This holds regardless of countries' heterogeneous preferences over the projects and follows from the fact that the bargaining positions of symmetric agents are exactly equal. Thus, negotiations will result in an equal split of the total surplus, which coincides with the efficient allocation. Second, when utility is quasi-linear with respect to consumption and all countries have symmetric marginal utilities of consumption then the budget is also raised and allocated efficiently, even though the allocations are redistributive. This result obtains since with quasi-linear utility, countries are able to utilize contributions as utility transfers. Lastly, we find that a large number of players will at least allocate (albeit not raise) the budget efficiently. This is due to the fact that as the union grows larger, the bargaining power of countries with high spillover projects increases. For a very large union, unstructured bargaining allocates all funds to the projects with the highest level of spillovers, which is also the efficient allocation.

These circumstances, even though they describe special cases, are educational. As

we analyze. Importantly, any country can veto the allocation of any money to the EU structural fund, independent of their participation in other EU institutions. Empirically, Bodenstein and Kemmerling (2011) show that even controlling for need there is still large variability in spending between regions, suggesting that the bargaining power of individual nations is important to the final allocation. 
long as a union consists of relatively homogeneous countries, or its budget is small relative to national domestic consumption levels and income levels are comparable, efficiency is achievable. In the presence of income asymmetry, however, unstructured bargaining generically leads to the budget being both raised and allocated inefficiently. In a number of numerical simulations, we show that inefficiencies are more severe the more unequal nations are ex-ante.

We go on to show that redistribution arises endogenously and is sustainable as a bargaining outcome, despite all nations being self-interested. In our model, a union can consist of net-contributing and net-receiving countries, while maintaining voluntary participation. The allocation of the budget achieved by bargaining is crucially determined by the distribution of bargaining power, which is in turn a function of both the contributions to the budget and the relative public good spillovers of the various projects. Therefore, countries that have access to projects with a high level of spillovers can end up receiving an allocation of the budget that is greater than their contribution to the joint funds.

When the correlation between a nation's income and the spillover effects from its preferred project is negative (as arguably is the case in the EU, where the most socially efficient projects are typically located in the poorer member states), the union is in principle able to achieve a level of redistribution that alleviates inequality between its members. However, precisely because of the link between contributions and allocations, there is an inherent efficiency-equity trade-off: The union cannot raise the contribution of any country without also increasing the allocation to its preferred project. A budget that will leave all union members equally well off is at the same time necessarily spent inefficiently. It follows that from a social welfare point of view, full redistribution, even if achievable, may not be desirable.

We also explore the potential of partial commitment, in the form of more complex institutional setups, to improve efficiency results. First, we consider using an exogenous tax rule to fix contributions, for example raising funds with a linear tax. Because of the link between contributions and allocations, adjusting contributions will improve efficiency on either the budget or allocation margin, but will necessarily decrease efficiency on the other margin. We find that at the Nash bargaining solution, it is always weakly optimal to improve the budget margin instead of the allocation margin. This suggests that tying contributions to incomes can improve general efficiency.

Second, we consider majority rule and legislative bargaining, as it breaks the link between contributions and allocations, at least for the countries in the minority. We show that majority rule can improve efficiency, but only if the countries with high spillover projects are endogenously chosen to form the majority. This occurs only if their relative contributions to the union budget are low enough. Therefore, in the case where income and spillovers are negatively correlated, majority rule and legislative bargaining can yield more efficient outcomes than unstructured bargaining. 


\section{Related literature}

So far, the understanding of union-level fiscal spending mainly derives from the literature on fiscal federalism. Lockwood (2002) analyzes the decision of a federation to supply a district-level public good with global spillovers. Due to legislative bargaining, centralization can result in inefficiencies since the majority coalition will not consider the welfare of districts outside of the coalition when determining outcomes. Similarly, Besley and Coate (2003) find that centralization can result in excessive public spending. Harstad (2007) considers the situation in which districts (or nations) have private information about their valuation of a public good and finds that a uniform federal (or union) policy mitigates the inefficiencies created by the private information. In contrast to fiscal policy administered within a federation, however, bargaining over fiscal outcomes at the supranational level is based on the implicit threat of veto. That is, the voluntary nature of supranational unions implies national participation constraints. Our paper emphasizes their existence as a major source of inefficiency. Yet, we show that if members bargain over outcomes under the threat of veto, centralized provision can result in efficiency in both allocation and spending, as long as districts have similar incomes and the level of spending on public goods is small relative to individual consumption.

Starting with the seminal paper by Grossman and Hart (1986), the distortion of ex-ante investment due to ex-post bargaining has received considerable attention outside the fiscal federalism literature. Harstad (2005) examines optimal majority rules when ex-post legislative bargaining over public good provision and transfers creates a hold-up problem that distorts ex-ante investment. Our paper considers a related, but distinct, problem that arises when "investments" are perfectly recoverable ex-post: We analyze how the inability to make binding ex-ante contracts over contributions and allocations distorts ex-post bargaining.

Our analysis of alternative institutions relates to the literature on optimal decision rules. Aghion and Bolton (2003) examine optimal majority rules in a model of legislative bargaining and find that districts (or nations) are willing to commit to a majority rule ex-ante given enough uncertainty regarding their ex-post preferences. Two recent papers explicitly consider supranational governance as an intergovernmental process with voluntary participation by member nations. Maggi and Morelli (2006) examine the optimal majority rule in a dynamic setting, where a single union project is repeated over time. If nations are patient enough, and are sufficiently uncertain about their future preferences, then the optimal majority rule can be supported even with voluntary participation. We analyze the inefficiencies that arise when uncertainty only occurs in the ex-ante constitution stage, and nations bargain over union outcomes after the resolution of uncertainty.

The paper most related to ours is Alesina et al. (2005), who model international unions as institutions that regulate domestic policy, and compare the effect of uniform and non-uniform union policy on aggregate welfare and the equilibrium size of unions. Our paper takes a complementary approach to examine fiscal spending, where the union directly controls a centralized budget. To further clarify, Alesina et 
al.'s regulation approach constrains the allocation of each nation's project to equal that nation's contribution (they also explore a uniform subsidy and decentralized public good decisions). Therefore, their framework does not capture the bargaining and redistribution that occurs under a centralized fiscal program, which is precisely what we explore here.

The remainder of the paper is organized as follows: Section 2 introduces the basic setup, and is followed by the characterization of the relevant efficiency benchmarks in section 3. Then, section 4 analyzes the Nash bargaining solution, gives conditions under which efficiency is achievable, and discusses characteristics of the inefficiencies that generally result from the bargaining process. Section 5 shows that redistribution can arise endogenously in the unstructured bargaining setting, and derives a tradeoff between equality and efficiency. In section 6 , we proceed to analyze alternative institutions that may improve efficiency. We derive conditions under which majority decision rules can improve efficiency and explore alternative contribution schemes like a linear tax. Section 7 concludes with a discussion of the results.

\section{Setup}

There are $n$ ex-ante identical nations that may form a union. At stage zero, before incomes and preferences are revealed, ${ }^{5}$ countries would like to select an ex-post binding contract specifying individual contributions to a centralized budget as well as its allocation. However, countries do not have access to a technology that allows such commitment.

At stage one, each nation receives an income, $y$, and an individual preference parameter, $\alpha$, each drawn, without replacement, from a finite set. We assume that the drawing process is randomized such that each country faces a uniform probability distribution over all possible pairs. After uncertainty is revealed, we denote countries with subscripts $i=1, \ldots, n$.

At stage two, contributions to the union budget, as well as the allocation of that budget, are determined through a bargaining process, which we describe in more detail in section 4. Importantly, at the bargaining stage, each nation still retains the option to veto the union and withdraw its contribution.

\section{Technologies}

Each country can either consume its income domestically $\left(c_{i}\right)$ or contribute to a union-wide budget $\left(x_{i}\right)$. Contributions to the union budget must satisfy the nation's individual budget constraint

$$
c_{i}+x_{i} \leq y_{i} \quad \forall i
$$

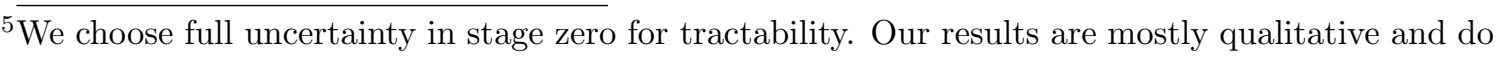
not change as long as some uncertainty over income and preferences remains at the initial stage.
} 
Moreover, we assume that $x_{i} \geq 0$ for all $i$. Together the contributions form the union's budget

$$
X=\sum_{i} x_{i}
$$

Forming a union allows the countries to implement a set of projects $\left\{g_{i}\right\}_{i=1}^{n}$. These joint projects produce according to a linear production function, so that the union wide budget constraint becomes

$$
\sum_{i=1}^{n} g_{i} \leq X
$$

with $g_{i} \geq 0$ for all $i$. The union projects essentially produce public goods that can be enjoyed by all members of the union.

We do not introduce a technology to directly transfer utility between nations. Realistically, there is no clear mechanism by which utility can be directly transferred at the supranational level. It is conceivable that "transfers" are made by increasing centralized spending in a given nation or by decreasing their contribution to the centralized budget, which is precisely what our model allows.

\section{Preferences}

Each nation receives utility from domestic consumption as well as the union projects. Among the joint projects, each nation values one particular project the most, but may benefit from (positive) spillover effects from other projects:

$$
U_{i}\left(c_{i}, g_{1}, \ldots, g_{n}\right)=u\left(c_{i}\right)+v\left(g_{i}+\sum_{j \neq i} \alpha_{j} g_{j}\right)
$$

We assume $u(\cdot)$ and $v(\cdot)$ are continuously differentiable, strictly increasing and concave, and satisfy standard Inada conditions. ${ }^{6} \alpha_{j}$ denotes the spillover effect a country gains from the implementation of project $g_{j}$. It is restricted to $\alpha_{j} \in[0,1)$. Thus, each project is valued most by the respective "home country," but produces weakly positive and symmetric spillovers for all other countries. ${ }^{7}$ We restrict utility over consumption and public-goods projects to be separable for tractability.

\footnotetext{
${ }^{6} \overline{\text { Specifically, we assume that } \lim _{x \rightarrow 0} u^{\prime}}(x)=\infty, \lim _{x \rightarrow 0} v^{\prime}(x)=\infty, \lim _{x \rightarrow \infty} u^{\prime}(x)=0$, and $\lim _{x \rightarrow \infty} v^{\prime}(x)=0$.

${ }^{7}$ More generally, we could write the utility country $j$ gains from being in the union as $v\left(\sum_{i} \alpha_{i j} g_{i}\right)$. In the analysis we restrict the spillover effects of each project $g_{i}$ to be symmetric across all but one countries, i.e. $\alpha_{i j}=\alpha_{i}$ for all $j \neq i$, and for country $i$ to strictly prefer project $g_{i}$ over all others, i.e. $\alpha_{i i}=1$. This restriction allows us to derive clean and intuitive expressions for the inefficiencies arising from bargaining. We point out when relaxing these constraints leads to additional interesting results.
} 
To economize on notation, we denote

$$
\begin{aligned}
& u_{i}^{\prime}=\frac{\partial u\left(c_{i}\right)}{\partial c_{i}} \\
& v_{i}^{\prime}=\frac{\partial v\left(g_{i}+\sum_{j \neq i} \alpha_{j} g_{j}\right)}{\partial\left(g_{i}+\sum_{j \neq i} \alpha_{j} g_{j}\right)},
\end{aligned}
$$

and define the ex-post individual surplus from setting up the union as

$$
S_{i} \equiv u\left(y_{i}-x_{i}\right)+v_{i}-u\left(y_{i}\right) .
$$

\section{Efficiency Benchmarks}

Since countries are ex-ante identical, a natural efficiency benchmark is the maximum expected utility surplus from implementing the union. ${ }^{8}$ Formally, a nation's expected individual utility surplus is defined as

$$
\mathbb{E}\left[S_{i}\right]=\mathbb{E}\left[u\left(y_{i}-x_{i}\right)+v_{i}-u\left(y_{i}\right)\right] .
$$

To simplify the analysis and to allow for explicit correlation structures between $y_{i}$ and $\alpha_{i}$ in our later analysis, we assume that each nation draws a pair $\left(y_{i}, \alpha_{i}\right)$, without replacement, from a set $S=\left\{\left(y_{i}, \alpha_{i}\right)\right\}$ with cardinality $n$. While this assumption excludes uncertainty over the aggregate profile of the union, it is without loss of generality with respect to our main results. ${ }^{9}$ The expected utility gain for each nation then is

$$
\mathbb{E}\left[S_{i}\right]=\frac{1}{n} \sum_{\left(y_{i}, \alpha_{i}\right) \in S} S_{i}\left(y_{i}, \alpha_{i}\right) .
$$

\footnotetext{
${ }^{8}$ This benchmark is analogous to the ex-ante expected utility benchmarks used in Harstad (2005) and Barbera and Jackson (2006). Moreover, the mechanism behind our main results persists even if there is some ex-ante certainty, as long as countries are identical with respect to the remaining uncertainty.

${ }^{9}$ If $y_{i}$ and $\alpha_{i}$ are drawn independently, multiple aggregate union profiles are possible. Associated with each profile, and with each $\left(y_{i}, \alpha_{i}\right)$ pair within a profile, is a corresponding surplus $S_{i}$. Denote with $\left\{S_{i}\right\}_{n}$ the ordered set of surpluses associated with each feasible union profile $\left(y_{i}, \alpha_{i}\right)^{n}$ and take $\mathbf{S}$ to be the set of all $\left\{S_{i}\right\}_{n}$. Let $m$ be the cardinality of $\mathbf{S}$. Since each profile is equally likely, and each country has an equal probability of being assigned to each pair, the expected utility surplus of the union is equal to $\sum_{\left\{S_{i}\right\}_{n} \in \mathbf{S}} \frac{1}{m} \sum_{S_{i} \in\left\{S_{i}\right\}_{n}} \frac{1}{n} S_{i}$. Full ex-ante efficiency then specifies that the inner sum, which is equal to aggregate ex-post utility, is maximized for each feasible union profile, which corresponds exactly to the problem (7) through (12).
} 
The set of efficient contributions $x_{i}$ and project allocations $g_{i}$ is thus the one that maximizes the aggregate utility surplus of the union:

$$
\begin{aligned}
\max _{\left\{c_{i}, x_{i}, g_{i}\right\}_{i=1, \ldots, n}} \sum_{i=1}^{n}\left[u\left(c_{i}\right)\right. & \left.+v\left(g_{i}+\sum_{j \neq i} \alpha_{j} g_{j}\right)\right] \\
\text { s.t. } \quad c_{i}+x_{i} & \leq y_{i} \quad \forall i \\
\sum_{i} x_{i} & =X \\
\sum_{i} g_{i} & \leq X \\
x_{i} & \geq 0 \quad \forall i \\
g_{i} & \geq 0 \quad \forall i .
\end{aligned}
$$

The optimality conditions to this problem imply the following definitions of potential efficiency benchmarks:

\section{Definition 1 (Efficiency Benchmarks)}

(I) Given a total budget $X$, a set of individual contributions $\left\{x_{i}\right\}$ is called BUDGETARY EFFICIENT if

$$
\begin{array}{cl}
u^{\prime}\left(y_{i}-x_{i}\right)=u^{\prime}\left(y_{j}-x_{j}\right) & \forall i, j \text { whenever } x_{i}, x_{j}>0 \\
u^{\prime}\left(y_{i}\right) \geq u^{\prime}\left(y_{j}-x_{j}\right) & \forall i \text { whenever } x_{i}=0 .
\end{array}
$$

(II) Given a total budget $X$, a set of project allocations $\left\{g_{i}\right\}$ is called ALLOCATIVE EFFICIENT if

$$
\begin{aligned}
& v_{i}^{\prime}+\alpha_{i} \sum_{j \neq i} v_{j}^{\prime}=v_{j}^{\prime}+\alpha_{j} \sum_{i \neq j} v_{i}^{\prime} \quad \forall i, j \text { whenever } g_{i}, g_{j}>0 \\
& v_{i}^{\prime}+\alpha_{i} \sum_{j \neq i} v_{j}^{\prime} \geq v_{j}^{\prime}+\alpha_{j} \sum_{i \neq j} v_{i}^{\prime} \quad \forall i \text { whenever } g_{j}=0 \\
& \sum_{i} g_{i}=X .
\end{aligned}
$$

(III) A set of contributions and allocations is called SOCIALLY EFFICIENT if it is budgetary and allocative efficient and the size of the total budget $X$ is such that

$$
u^{\prime}\left(y_{i}-x_{i}\right)=v_{i}^{\prime}+\alpha_{i} \sum_{j \neq i} v_{j}^{\prime} \quad \forall i
$$

Budgetary efficiency (I) prescribes that contributions should be diverted where it is least costly in terms of forgone consumption, whereas allocative efficiency (II) requires funds to be spent such that the union makes best use of all available technologies. Both benchmarks describe technological aspects of efficiency. Social efficiency (III) on the other hand also dictates the size of the centralized budget. Since 
union-level spending is the only channel for inter-country redistribution available, concerns regarding the redistribution of income, rather than gains from coordination, pin down the optimal budget size. However, the size of the budget might be limited by ex-post political constraints on the degree of redistribution within the union. Therefore, we focus on the first two dimensions of efficiency defined for any given budget. If an allocation satisfies both (I) and (II), we refer to it as efficient. The reader may interpret the size of the union budget $X$ compared to aggregate GDP among the countries as a measure of importance of the intended union. ${ }^{10}$ Because the total budget $X$ is set exogenously, and since utility is separable between the consumption good and public goods projects, the definitions of budgetary (I) and allocative (II) efficiency are not connected. Either benchmark could be reached without the other being satisfied.

It is important to note that at the efficient allocation, there is no connection between what each specific country contributes to the budget and how much is allocated to its preferred project. However, when nations bargain, we will see that there is a link between their contributions and the allocation. Naturally, contributions influence the bargaining position of each nation. This is the source of inefficiency at the heart of this paper. In what follows we will discuss how exactly the bargaining process between nations distorts the two efficiency margins and derive conditions under which the bargaining outcome achieves both budgetary and allocative efficiency.

\section{Nash Bargaining}

In this section, we study the union's budget negotiations as an unstructured bargaining process. Unstructured bargaining is both the least complex institution for raising and allocating funds (from a political perspective), and is the institution most commonly used by the EU for fiscal spending programs. Formally, countries bargain à la Nash over the utility surplus created by the union. The Nash bargaining solution is tailored to situations where no specific institutions govern the bargaining process and each participant is a veto player, and is therefore the appropriate solution concept for our model. ${ }^{11}$

We assume that countries have equal ex-ante bargaining weights, so that the result-

\footnotetext{
${ }^{10}$ Note, however, that setting the total union budget exogenously does not mean that participation constraints are assumed to hold exogenously as well. In the bargaining process analyzed below, the outside option for every nation remains to withdraw from the union and consume all income domestically, regardless of whether the budget is determined exogenously or through a bargaining process. Therefore, the results we present in the following section all extend to the case where countries also bargain over the size of budget. In Appendix A, we give a detailed discussion on the justification of the assumptions made about the efficiency benchmark and show that an additional result pertains when $X$ is chosen endogenously as well.

${ }^{11}$ Under alternative coalition-based approaches the fundamental link between contributions and allocations that we seek to analyze would be retained. Moreover, regarding EU budget negotiations, veto power is a realistic assumption.
} 
ing allocation solves the following problem: ${ }^{12}$

$$
\begin{aligned}
\max _{\left\{x_{i}, g_{i}\right\}_{i=1, \ldots, n}} & \prod_{i=1}^{n}\left[u\left(y_{i}-x_{i}\right)+v\left(g_{i}+\sum_{j \neq i} \alpha_{j} g_{j}\right)-u\left(y_{i}\right)\right] \\
\text { s.t. } & \sum_{i} g_{i} \leq X \\
& \sum_{i} x_{i}=X,
\end{aligned}
$$

as well as $x_{i}, g_{i} \geq 0$ for all $i$. The disagreement point is for all countries to revert to autarky and consume their individual income $y_{i}$.

With the power to veto, participation constraints gain an important role in determining the bargaining outcome. No country can be worse off in the union than it would be under autarky. Moreover, the Nash bargaining solution reflects a compromise that weighs each player's payoff in the union against his outside option. The value of the union to each player, however, is endogenous to the specific set of contributions and allocations in question. The Nash bargaining solution takes this into account - the distribution of bargaining power is endogenous.

For example, suppose that a proposed contribution schedule specifies a larger contribution for one country than another, even though they have the same income. For the former not to veto such a schedule, a disproportionate amount of funds must be allocated to its preferred - albeit not necessarily more efficient - project. The higher contribution increases that nations outside option and so its de facto bargaining position when negotiating the allocation of funds. This link of contributions to allocations via the implied bargaining power is an important source of inefficiency that has not been previously explored.

We analyze the problem as if nations were choosing both contributions and allocations simultaneously. Even if nations in reality sometimes bargain first over contributions and then separately over allocations, we are interested in situations where their outside option in the second step remains to withdraw from the union and consume their contribution. Then, a two-step procedure does not break the link between contributions and the nations' bargaining positions in the second step. It is easy to verify - assuming nations choose subgame-perfect strategies in the first step - that the resulting allocation is indifferent to whether the analysis is done in one or two steps. In this respect our setup differs crucially from the bargaining games analyzed by Harstad (2005), where contributions from the first stage are fixed in the second stage and create a hold-up effect that influences the incentive structure of the whole game.

We do not model the bargaining process explicitly. However, the Nash bargaining solution and hence the distribution of surpluses reflects the underlying bargaining

\footnotetext{
${ }^{12}$ The Nash bargaining solution assumes that agents bargain over a convex set of utility outcomes. As noted in Conley and Wilkie (1996), however, the set of utility outcomes is not generally convex when spillovers are present. In Appendix B, we prove that the Nash bargaining solution extends to the relevant non-convex sets.
} 
position of each nation. Hence, we can interpret the set $\left\{S_{i}\right\}$ as a statistic about the implied bargaining positions. Naturally, this setup does not allow us to explicitly measure bargaining power. Instead we analyze how changes in the underlying parameters affect the distribution of surpluses and thus imply relative changes in bargaining positions. With that caveat in mind, we refer to the bargaining positions implied by the primitives of the model as bargaining power.

\subsection{Bargaining over Allocations}

We start by solving only a subpart of the full problem to illustrate the main source of inefficiency. Taking the set of contributions as exogenously given, but maintaining the outside options for nations to withdraw them, will illustrate the respective connection between budgetary contributions $\left(x_{i}\right)$ and technological contributions $\left(\alpha_{i}\right)$ to the implied bargaining position.

Suppose that two countries, $i=a, b$, bargain only over allocating funds to the set of projects $\left\{g_{a}, g_{b}\right\}$, while their contributions $\left\{x_{a}, x_{b}\right\}$ to the union budget are fixed ex-ante. In this case, the bargaining problem simplifies to:

$$
\begin{aligned}
& \max _{\left\{g_{a}, g_{b}\right\}}\left(S_{a}\right)\left(S_{b}\right) \\
& \text { s.t. } g_{a}+g_{b} \leq X .
\end{aligned}
$$

Since Nash bargaining selects among the set of ex-post Pareto optimal points, constraint (20) is binding. The resulting maximization problem is concave, which allows us to use the first-order-conditions to implicitly solve for the equilibrium level of $g_{a}$ and $g_{b}$ :

$$
v_{a}^{\prime} S_{b}+\alpha_{a} v_{b}^{\prime} S_{a}=v_{b}^{\prime} S_{a}+\alpha_{b} v_{a}^{\prime} S_{b} .
$$

Equation (21) illustrates some basic properties of the bargaining solution. It states that the allocation the two nations will compromise on will not equalize the marginal returns of the two union projects unless $S_{a}=S_{b}$ (a special case we discuss below). Instead, the Nash bargaining outcome represents a balance between efficiency (equalizing the marginal returns of the projects) and bargaining power, which depends on the players' outside options and thus their contributions. This illustrates the main insight: Since outside options influence bargaining power, the bargaining process generally distorts efficiency.

We can reorganize Equation (21) as follows:

$$
\frac{\left(1-\alpha_{b}\right) v_{a}^{\prime}}{\left(1-\alpha_{a}\right) v_{b}^{\prime}}=\frac{S_{a}}{S_{b}} .
$$

which clearly illustrates the correspondence between the primitives of the model and the implied distribution of bargaining power. First, equation (22) implies a positive relationship between $x_{a}$ and $g_{a}$, since $S_{a}$ is decreasing $x_{a}$ and $v_{i}^{\prime}$ is decreasing in $g_{i}$. It is not always obvious, however, which player has the larger bargaining power and will tilt the allocation toward his preferred project. Bargaining power is also an 
increasing function of the project spillovers $\alpha_{i}$ since, by equation (22), an increase in $\alpha_{a}$ results in a higher ratio of $S_{a}$ and $S_{b}$.

To explore the relationship between contributions, spillovers and efficiency, suppose countries are symmetric, i.e. $y_{a}=y_{b}=y$ and $\alpha_{a}=\alpha_{b}=\alpha$. However, their contributions to the joint budget are exogenously set to differ such that $x_{a}>x_{b}$. The efficient allocation of the joint funds would be $g_{a}=g_{b}=g$, regardless of the difference in contributions, implying

$$
\frac{\left(1-\alpha_{b}\right) v_{a}^{\prime}}{\left(1-\alpha_{a}\right) v_{b}^{\prime}}=\frac{(1-\alpha) v^{\prime}}{(1-\alpha) v^{\prime}}=1 .
$$

At this allocation, surpluses $S_{a}$ and $S_{b}$ would be

$$
S_{a}=u\left(y-x_{a}\right)+v((1+\alpha) g)-u(y)<u\left(y-x_{b}\right)+v((1+\alpha) g)-u(y)=S_{b},
$$

so that $S_{a} / S_{b}<1$. Thus, condition (22) is not satisfied at the efficient allocation. The Nash bargaining outcome in this case would be such that $g_{a}>g_{b}$ and thus inefficiently allocate too much to project $g_{a}$. Nation a's larger opportunity cost of participating in the union increases its relative bargaining position, and it is able to skew the allocation in its favor.

Similarly, suppose countries are symmetric in incomes and contributions, but not project spillovers; i.e. $y_{a}=y_{b}=y, x_{a}=x_{b}=x$, and $\alpha_{a}>\alpha_{b}$. The efficient allocation of the joint funds in this case specifies $g_{a}^{*}>g_{b}^{*}$ so that the marginal returns of both projects are equalized: $\left(1-\alpha_{b}\right) v_{a}^{\prime}=\left(1-\alpha_{a}\right) v_{b}^{\prime}$. At this allocation, $S_{a}>S_{b}$.

As equation (22) demonstrates, if countries are otherwise symmetric, the Nash bargaining outcome does allocate more to the higher spillover project $\left(g_{a}>g_{b}\right)$. At the efficient allocation, however, since $\left(1-\alpha_{b}\right) v_{a}^{\prime}=\left(1-\alpha_{a}\right) v_{b}^{\prime}$ the following expression would hold:

$$
\frac{\left(1-\alpha_{b}\right) v_{a}^{\prime}}{\left(1-\alpha_{a}\right) v_{b}^{\prime}}<\frac{S_{a}}{S_{b}}
$$

which when compared to equation (22) demonstrates that despite skewing the allocation towards $g_{a}$, the Nash bargaining outcome still under-funds $g_{a}$ : i.e. $g_{b}<g_{a}<g_{a}^{*}$.

The discussion in this section highlights the two channels through which the primitives of the model influence the bargaining outcome. The implied distribution of bargaining power is determined both by the utility values of the nations' contributions and the spillovers of their projects. In what follows, we show that this sensitivity of the outcome to the distribution of bargaining power among the players generically distorts efficiency.

\subsection{Joint Bargaining over Funds and Allocation}

We proceed by formally analyzing the full bargaining setup over both contributions to the joint budget and its allocation to the union projects. For expositional sim- 
plicity, we present the main results for the special case of $n=2$ countries. All formal proofs are done for a general number of countries and relegated to the appendix.

The allocation that solves the general Nash bargaining problem (16) through (18) for two countries is characterized by the following conditions for optimality:

$$
\begin{aligned}
\frac{u_{a}^{\prime}}{u_{b}^{\prime}} & =\frac{S_{a}}{S_{b}} \\
\frac{v_{a}^{\prime}}{v_{b}^{\prime}} & =\frac{\left(1-\alpha_{a}\right)}{\left(1-\alpha_{b}\right)} \frac{S_{a}}{S_{b}} \\
g_{a}+g_{b} & =X \\
x_{a}+x_{b} & =X .
\end{aligned}
$$

We first discuss two special cases when the Nash bargaining solution does achieve general efficiency. Their existence is remarkable, because they depict conditions under which a union of countries achieves an efficient allocation simply through unstructured bargaining. That is, under some conditions, simply sitting in a room and negotiating a compromise works at least as well as any other more structured institutional setup could.

\section{Proposition 1 (Symmetry implies efficiency)}

If countries are ex-post perfectly symmetric, i.e. $y_{a}=y_{b}$ and $\alpha_{a}=\alpha_{b}$, then, for any budget $X$, the Nash bargaining solution satisfies both budgetary and allocative efficiency.

\section{Proof: See Appendix C.1.}

Since all countries have the same endowment, their opportunity costs of contributing to the joint budget are the same. Moreover, symmetric spillovers do not give one country a higher incentive to participate in the union than the other. Consequently, both countries have the exact same bargaining position. Thus, an equilibrium in the bargaining game must produce equal surpluses $S_{i}$ for the two nations. At this particular point, the efficient allocation also produces the same surplus $S_{i}$ for each nation, so that it coincides with the Nash bargaining solution. It is important to notice, though, that symmetric income and spillovers do not imply homogeneous preferences: Each nation still prefers its "own" project over the others. Instead, symmetry leads to a perfectly uniform distribution of bargaining power in equilibrium.

\section{Proposition 2 (Quasi-linearity implies efficiency)}

If preferences are quasi-linear in domestic consumption, i.e. $U_{i}=c_{i}+v\left(g_{i}+\alpha_{j} g_{j}\right)$, then, for any budget $X$, the Nash bargaining solution satisfies both budgetary and allocative efficiency.

Proof: See Appendix C.2.

Quasi-linear preferences reduce the effect of opportunity costs of funds on the bargaining position of each player to a simple linear relationship (since one unit of 
domestic consumption is valued the same at any income level). Effectively, bargaining simply sets the allocation that maximizes the total surplus and then sets contributions such that the utility surplus is split equally. Allocative efficiency is defined as maximizing the total return from the union projects, so the Nash bargaining solution in this case is allocative efficient. Moreover, in case of quasi-linear preferences, budgetary efficiency $\left(u_{a}^{\prime}=u_{b}^{\prime}\right)$ is met regardless of the domestic consumption allocation.

The case of quasi-linear preferences has the following standard interpretation: A quasi-linear utility function can be used to approximate an underlying, strictly concave, utility function when spending on a single good is small relative to overall consumption. Proposition 2 requires the additional condition that the slopes of the utility function over consumption are equal, since budgetary efficiency can only be achieved if the countries have the same marginal utilities of income. Arguably, this is an appropriate assumption if the countries in the union have similar income levels and are therefore at the same point on the underlying, strictly concave, utility function. Combined, the above implies the following interpretation of Proposition 2: If union spending is small relative to domestic consumption and the union is composed of countries with homogeneous income levels, then Nash bargaining will give efficiency.

Before analyzing the properties of the Nash bargaining solution more generally, we address corner solutions. If, for example, spillovers are very asymmetric, it may happen that it is efficient to fund only one of the projects. Equivalently, very asymmetric domestic incomes may call for the union activities being funded by the richest country exclusively. It turns out that the Nash bargaining solution can, in some cases, achieve these efficient corners ${ }^{13}$ as well, even though neither conditions of Propositions 1 or 2 are satisfied.

\section{Lemma 1 (Corners)}

There exist Nash bargaining corner solutions that are budgetary and/or allocative efficient.

\section{Proof: See appendix C.3.}

The lemma states that there can also be efficient "double corners" where the complete budget is provided by only one country and allocated to only one project. We do not consider this case to be particularly relevant or interesting, ${ }^{14}$ and therefore

${ }^{13}$ It should be noted again, though, that efficient corners only arise because contributions and projects are restricted to be non-negative. At an efficient corner solution, marginal utilities are not equalized, as described in the efficiency definitions (I) and (II).

${ }^{14}$ There are two scenarios that constitute a "double corner": The first is when the same country contributes and receives the complete budget. This case maps to a classic public good problem and union dynamics do not play a role. The second scenario has one country contribute the complete budget and another country receive all the funds, which intuitively resembles foreign aid or foreign direct investment. Both are not relevant in the context of a supranational union of sovereign countries that is the focus of our paper. There are, however, institutional examples where some countries contribute, but do not receive funding (e.g. the EU cohesion funds), and where some countries receive funding, but do not contribute (e.g. the World Bank). Such "single 
exclude it from the subsequent analysis.

Suppose from now on that $u(\cdot)$ is strictly concave.

\section{Proposition 3 (Inefficiency from bargaining)}

Generically, the efficient allocation cannot be supported as a Nash bargaining solution.

\section{Proof: See Appendix C.4.}

Efficiency requires the allocation of available resources to the highest return technologies. Ideally, marginal returns of all union projects are equalized and funds raised where it is least costly, without regard of each country's individual gain. When bargaining, however, each individual country considers its own surplus only. How well it is able to push for its preferred allocation depends on its relative bargaining position toward the other players. The efficient allocation of funds, on the other hand, almost never implies a ratio of surpluses consistent with the implied distribution of bargaining power, because it doesn't take into account how differences in income or the spillover effects of projects benefit one country more than another.

Given the efficiency results derived above, the outcome of an unstructured bargaining process may sometimes not be very far from efficient. The purpose of the remainder of this section is to understand under which circumstances the inefficiencies are severe and which of the efficiency margins is typically distorted.

Suppose parameters are such that the efficient allocation is not a corner solution.

\section{Corollary 1 (Both efficiency margins are distorted)}

When the Nash bargaining outcome does not coincide with the efficient allocation, it distorts both budgetary and allocative efficiency.

\section{Proof: See Appendix C.5.}

In the commonly relevant case where the asymmetry in terms of income and spillovers of the proposed projects is not extreme, both margins of efficiency are distorted. This complicates the direct measurement of inefficiency and thus the comparison of different scenarios. In fact, the Nash bargaining solution is not monotone with respect to changes in asymmetry in either income or spillovers.

To nonetheless gain some intuition about the order of magnitude of inefficiencies, we numerically explore different scenarios of parameter combinations for a simple example with the following form of log-preferences:

$$
U_{i}=\log \left(c_{i}\right)+\log \left(g_{i}+\alpha_{j} g_{j}\right) \quad \text { for } i=a, b .
$$

The following three simulations confirm that inefficiencies grow more than proportionally with the degree of asymmetry between nations. Moreover, we show that the distortion is more severe on the allocation margin when asymmetry is in terms

corners" are not excluded from our analysis, unless otherwise noted. 
of incomes (experiment 1), but more severe on the contribution margin if spillovers are asymmetric (experiment 2). Generally, efficiency is most distorted when both incomes and spillovers are asymmetric and there is a negative correlation between the two (experiment 3).

First, suppose spillovers are symmetric, i.e. $\alpha_{a}=\alpha_{b}$. Keeping aggregate income constant, we vary asymmetry in domestic incomes (experiment 1). Figure 1 shows the Nash bargaining outcome compared to the generally efficient solution. As country a's income increases, so does its outside option and thus its bargaining position relative to country $b$ in equilibrium, leading to an inefficient outcome. The allocation of funds to the union projects (upper right panel) depicts this channel very clearly: While the efficient allocation is independent from the distribution of national incomes, the Nash bargaining solution reflects the changing distribution of power. Nation $a$ is able to tilt the allocation more toward its own preferred project the higher its income. Moreover, it is able to negotiate a "discount" for its contribution. While $x_{a}$ increases with $y_{a}$, country $a$ pays less than would be budgetary efficient given its higher income (upper left panel). As a result of the inefficiencies introduced by the bargaining process, aggregate utility in the union, and hence expected ex-ante individual utility, declines as asymmetry grows. Notice, however, that the loss in aggregate utility is relatively small when asymmetry is small, but grows more than proportionally as the countries become more and more unequal (lower right panel).
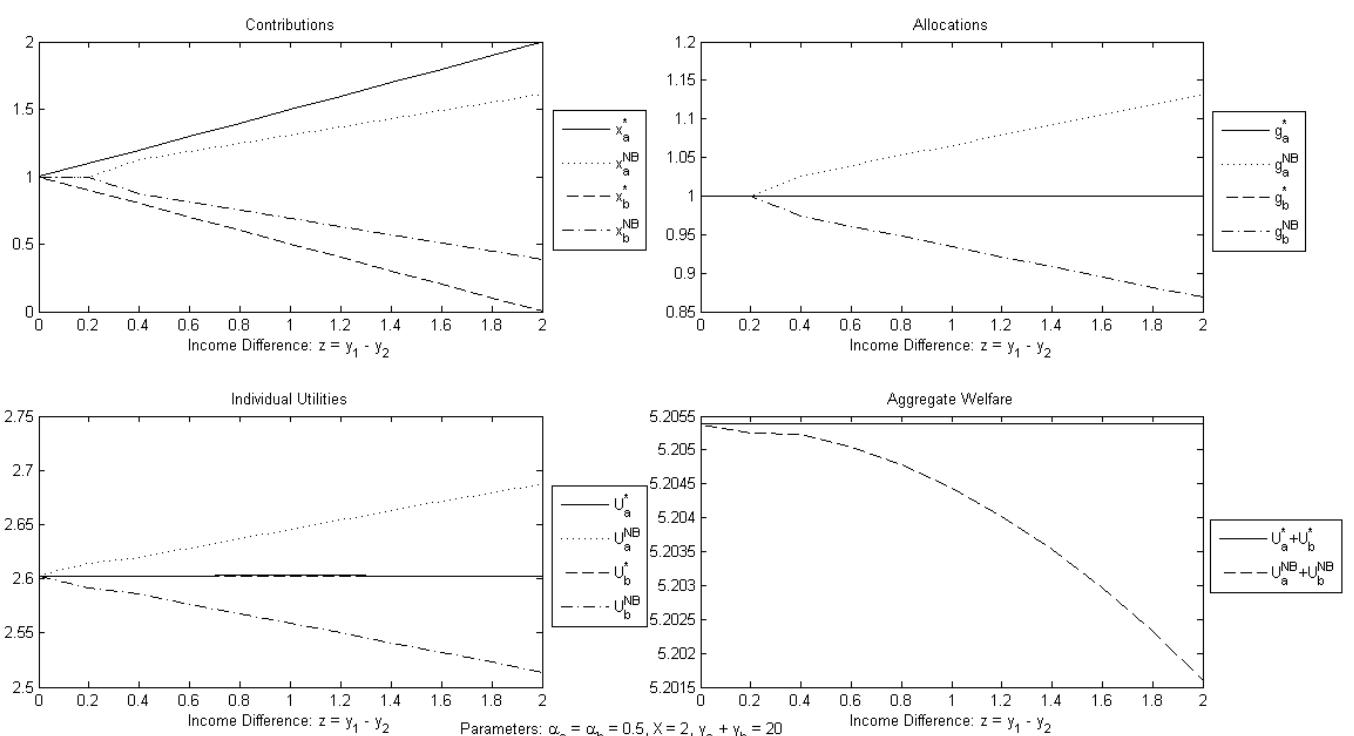

Figure 1: Asymmetry in income

Next, we present a similar experiment, keeping symmetric endowments, but varying the spillover effects of the projects (experiment 2). The change in technology has a direct impact on aggregate utility at the efficient solution. For a meaningful comparison between the efficient and the Nash bargaining solution, we vary spillovers such that aggregate utility remains constant. ${ }^{15}$ Figure 2 shows similar results as before:

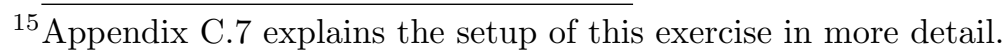


Here, as $\alpha_{b}$ increases, funds should efficiently be re-allocated toward project $g_{b}$, while contributions should remain unchanged. At this efficient allocation, however, nation $a$ 's surplus would be smaller than nation $b$ 's, ${ }^{16}$ leading to a increase in bargaining power of nation $a$ relative to nation $b$. Consequently, the outcome of the bargaining process is again skewed in $a$ 's favor. The contributions of country a decrease away from the efficient level (upper left panel) and at the same time the allocation of union funds tilts toward $a$ 's preferred project $g_{a}>g_{a}^{*}$ (upper right panel). Again, the loss in aggregate welfare is small initially, but increasing as asymmetry grows (lower right panel).
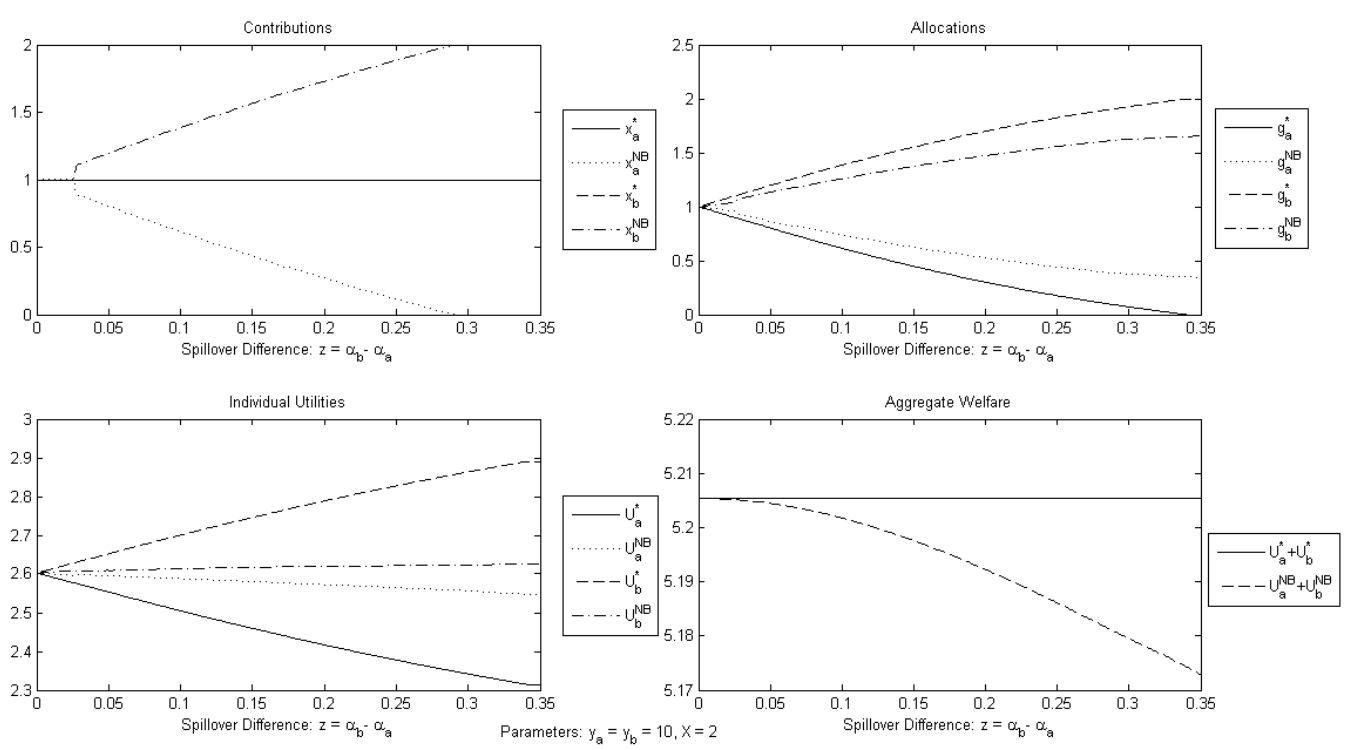

Figure 2: Asymmetry in spillovers

Finally, we compare two scenarios with asymmetry in both income and spillovers (experiment 3). Again, as in the first experiment, we vary income inequality, while keeping aggregate income unchanged. However, here in the left column there is a negative correlation between income and spillovers, while in the right column, income and spillover effects are positively correlated.

Figure 3 shows that the allocation of the union budget to the projects is more efficient when income and spillovers are positively correlated. This is intuitive: The nation with the increase in income increases its bargaining power and is therefore able to tilt the distribution of funds toward its preferred project. When income and spillovers are positively correlated, this happens to be the efficient project.

Generally, the overall distribution of bargaining power and resulting allocation in the Nash bargaining equilibrium is non-monotone in measures of asymmetry. It may in fact even happen that growing asymmetry has a positive effect on aggregate utility, as the lower right panel of Figure 3 shows.

${ }^{16}$ This follows since at the efficient allocation $v_{a}^{\prime}\left(1-\alpha_{b}\right)=v_{b}^{\prime}\left(1-\alpha_{a}\right)$, so that with $\alpha_{a}<\alpha_{b}$ we get $v_{a}<v_{b}$ 

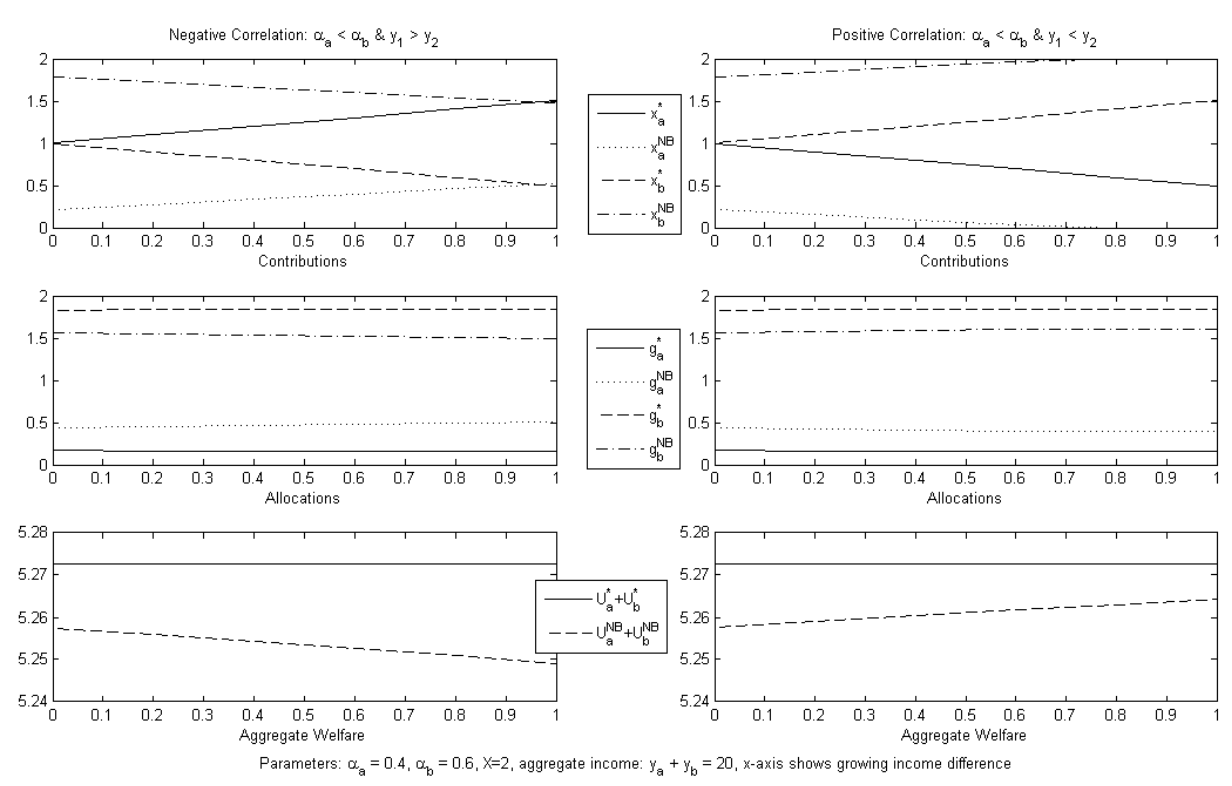

Figure 3: Asymmetry in spillovers

\subsection{More than two countries}

Some interesting additional results obtain when more than two countries bargain. The Nash bargaining solution with $n>2$ is characterized by:

$$
\begin{array}{rlr}
\frac{u_{i}^{\prime}}{u_{j}^{\prime}} & =\frac{S_{i}}{S_{j}} & \forall i, j \\
v_{i}^{\prime}\left(1-\alpha_{j}\right) & =v_{j}^{\prime}\left(1-\alpha_{i}\right) \frac{S_{i}}{S_{j}}-\left(\alpha_{i}-\alpha_{j}\right) \sum_{k \neq i, j} v_{k}^{\prime} \frac{S_{i}}{S_{k}} & \\
\sum_{i=1} g_{i} & =X & \\
\sum_{i=1} x_{i} & =X &
\end{array}
$$

where again $S_{i}=u\left(y_{i}-x_{i}\right)+v_{i}-u\left(y_{i}\right)$ denotes the surplus generated for country $i=1, \ldots, n$ respectively.

Note that equation (30) remains the same as in the two-country case (compare to equation (26)), implying that the relative split of utility surplus between country $i$ and country $j$ is still determined by the ratio of their marginal utilities from domestic consumption. Equation (31), which defines the relative allocation of funds between countries $i$ and $j$, however, has the additional term $\left[\left(\alpha_{i}-\alpha_{j}\right) \sum_{k \neq i, j} v_{k}^{\prime} \frac{S_{i}}{S_{k}}\right]$. This shows that the relative allocation of funds reflects the impact of country $i$ 's spillovers on all other countries, not just country $j$.

From these conditions it is clear that the results of Propositions 1 and 2 extend to the case of more than two countries, since efficiency is obtained under Nash bargaining 
when $S_{i}=S_{j}$ for all $j, i{ }^{17}$

Expanding the analysis to a general number of countries allows us to study the impact of the size of the union on efficiency. Formally, we define the size of the union as follows:

\section{Definition 2 (Union Size)}

Take $Z$ to be an infinite ordered sequence of countries: $Z=\left\{\left(\alpha_{1}, y_{1}\right),\left(\alpha_{2}, y_{2}\right), \ldots\right\}$. $A$ union of size $n$ consists of a union of the first $n$ countries in $Z$.

Then:

\section{Proposition 4 (Efficient allocation in large unions)}

For any sequence of countries, $Z$, there exists an $N$ such that for any union of size $n \geq N$, unstructured bargaining yields ALLOCATIVE efficiency.

Proof: See Appendix C.6.

Proposition 4 suggests that very large unions are better able to allocate funds and therefore closer to optimal. This argument, however, is driven by the fact that, in our model, there are no diminishing returns to spillovers. Therefore, the addition of a new country will always increase aggregate surplus. Another way to characterize the result is that adding additional countries to the union increases the relative bargaining power of countries with high spillover projects. This effect is not dependent on the property of no diminishing returns. This interpretation implies that, as the union grows, it will stop funding the most inefficient projects, i.e. those with the lowest level of spillovers.

\section{Endogenous Redistribution}

In this section, we show that redistribution can arise endogenously in a union of sovereign nations who participate voluntarily - despite a lack of altruistic preferences, any uncertainty at the bargaining stage warranting an insurance mechanism, or a repeated game structure justifying mutual favors. However, when considering the size of the budget, there exists a trade-off between increasing equality and decreasing efficiency. Moreover, under relevant parameter restrictions, this trade-off becomes more severe as the centralized budget increases.

A social planner would naturally distribute resources from domestic consumption to the union projects without regard of each nation paying as much as it receives in funding to its preferred project. We show that without an overarching authority dictating the outcome, such resource redistribution is still sustainable. In fact, the Nash bargaining solution almost always redistributes resources between the members of the union:

\footnotetext{
${ }^{17}$ See Appendix $\mathrm{C}$ for the formal proofs.
} 


\section{Proposition 5 (Endogenous Redistribution)}

Generically, $g_{i} \neq x_{i}$.

Proof: See Appendix D.1.

Being a net-contributor, however, does not necessarily mean that the nation loses with respect to other union members. After all, the participation constraints ensure that every nation is better off in the union than under autarky. Rather than concentrating on resource redistribution, it is much more interesting to ask who gains the most under which circumstances. Again, what matters is a comparison of the surpluses $S_{i}$ from joining the union. As we have seen before, comparative statics with respect to the underlying parameters are highly non-linear. To make progress, we focus attention on the case where the participating nations have a negative correlation between income and spillovers of their most preferred projects, i.e. the highest return projects are located in the poor member countries of the union.

\section{Proposition 6}

If $y_{a}>y_{b}$ and $\alpha_{a}<\alpha_{b}$, then $S_{a} \leq S_{b}$.

\section{Proof: See Appendix D.2.}

The proposition states that the richer country always gains weakly less from the union than the poorer nation. Since the surplus for both countries must be positive, this is still not conclusive evidence for a change in inequality. Whether or not the difference between the nation's utility changes with respect to ex-ante inequality $u\left(y_{a}\right)-u\left(y_{b}\right)$, and in which direction, crucially depends on the size of the union budget $X$.

\section{Proposition 7 (Decreasing Inequality)}

For any parameter combination such that $y_{a}>y_{b}$ and $\alpha_{a}<\alpha_{b}$, there exists a budget $X$ such that $u\left(c_{a}\right)+v\left(g_{a}+\alpha_{b} g_{b}\right)-u\left(c_{b}\right)-v\left(g_{b}+\alpha_{a} g_{a}\right)<u\left(y_{a}\right)-u\left(y_{b}\right)$.

\section{Proof: See Appendix D.3.}

This result shows that when a nation with high income but a low spillover project negotiates to form a union with a low-income but high-spillover nation, inequality of utility between the nations can be guaranteed to drop by choosing the right budget $X$. We have taken $X$ as exogenously given because of the redistributive motive inherent in its choice. ${ }^{18}$ In reality, ex-post political constraints most likely influence the desired level of redistribution. The following analysis helps to guide this process by pointing out the trade-offs involved in picking a centralized budget. The proof of Proposition 7 only states that there is always a budget small enough to decrease inequality. How much potential there is for reducing inequality through the union depends on the specific parameters. Moreover, while increasing the budget $X$ away from zero will initially decrease inequality between the nations, it also has a downside: In the unstructured bargaining process, redistributive contributions influence

\footnotetext{
${ }^{18}$ See Appendix A.3 for a discussion of our results when $X$ is chosen endogenously as well.
} 
the distribution of bargaining power, which has a crucial impact on the efficiency of allocating the funds to the union projects.

\section{Proposition 8 (Equality-Efficiency Trade-off)}

If $y_{a}>y_{b}$ and $\alpha_{a}<\alpha_{b}$, all else equal, increasing the net-contribution of nation $a$ will result in a less efficient allocation of the joint funds.

\section{Proof: See Appendix D.4.}

While letting the richer nation contribute more to the joint budget may seem desirable to achieve less inequality, it will necessarily bargain for a higher allocation of funds to its own preferred, but relatively less valuable, project. Therefore, while a budget can be picked to alleviate the utility differences between the rich and poor country, this comes at the cost of an increasingly inefficient allocation of funds. In the bargaining process, since bargaining power is linked to contributions, redistribution arises endogenously. This, however, causes inefficient allocations at the same time. Therefore, when picking the total budget, policy makers must trade-off welfare gains from increased equality against efficiency losses.

Inefficiency occurs along two dimensions: budgetary contributions and allocation of funds. We present a numerical example to illustrate how initial income inequality determines which of these margins is affected most in the equality-efficiency tradeoff. Figure 4 shows two scenarios in which a high income nation $a$ and a low income nation $b$ bargain over the union allocation. In both cases there is a negative correlation between income and spillovers; the right column shows a higher income asymmetry between the two countries.
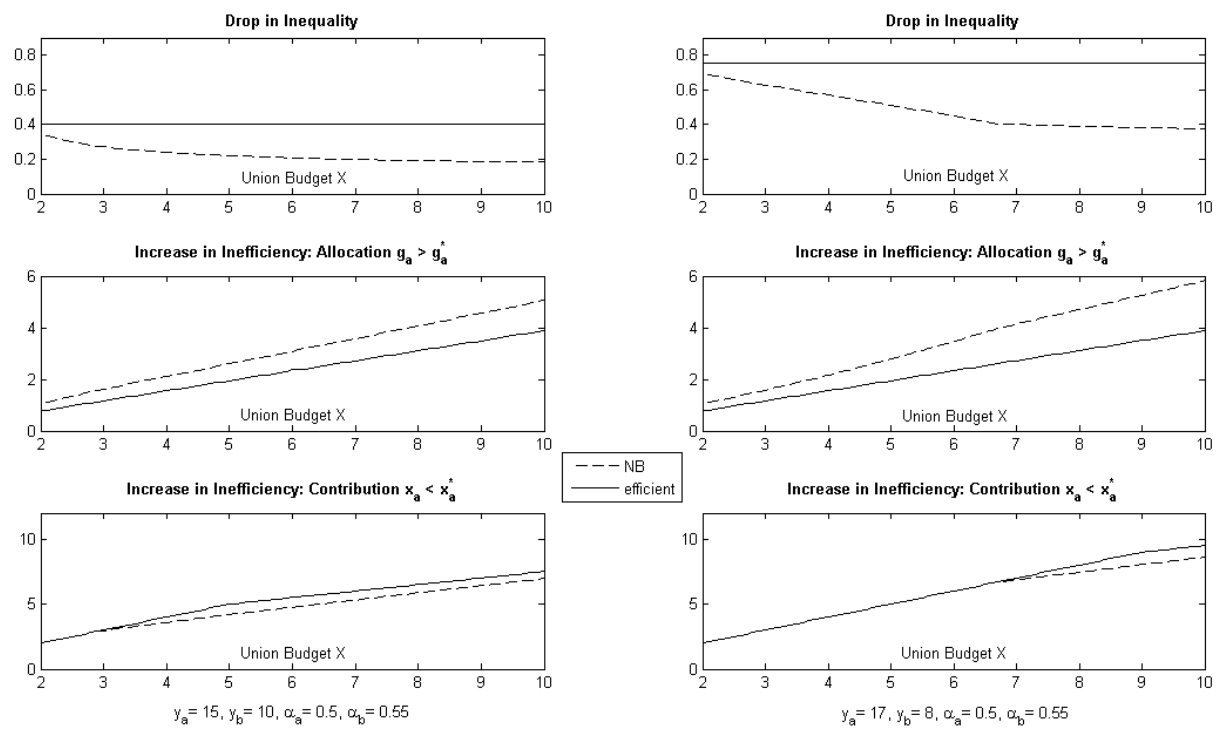

Figure 4: Ex-ante vs. ex-post inequality for varying budgets

We plot ex-ante vs. ex-post inequality in the first row panels. Here we see that a larger budget $X$ leads to more equality. The two rows below show the simultaneous 
increase in inefficiency: At higher levels of equality, more is allocated to the relatively inefficient project $g_{a}$, and nations $a$ 's contribution decreases further away from the budgetary efficient one. Consequently, the overall increase in equality comes at the cost of a decrease in aggregate welfare - this is the equality-efficiency trade-off.

Comparing the left and right column reveals that higher ex-ante inequality leads to more severe allocative inefficiency, but less budgetary inefficiency. Because preferences are concave, the high-income nation finds it cheaper to agree to a higher contribution and uses its higher implicit bargaining power to tilt the allocation of funds further to its own preferred project. Thus, the more nations differ in income, the more severe is the trade-off between equality and allocative efficiency.

\section{Alternative Institutions}

So far, we have considered the case of no ex-ante commitment and analyzed the resulting bargaining outcome. In this section, we explore the potential of partial ex-ante commitment in the form of alternative decision-making institutions. While unstructured bargaining and unanimity remains the norm for current EU fiscal programs, the fact that the EU uses qualified majority voting in other areas suggests that partial commitment might be available in the supranational setting. In particular, we examine tax rules that pin down contributions as a function of income ex-ante, and majority decision rules over the allocation of the budget. We detail when these institutions outperform Nash bargaining, again concentrating on the case in which spillovers and income are negatively correlated. As we saw in the previous section, the positive link between contributions and bargaining power allows for some resource redistribution from high to low income nations, but at the same time prevents the fully efficient use of the budget, so that there is potential room for improvement using instruments with a clear redistributive motive.

\subsection{Exogenous Tax Rules}

In this subsection, we consider partial commitment in the form of ex-ante determination of $x_{i}$ as a function of $y_{i}$. For example, countries may restrict contributions to be a proportional share of national income (a linear tax). To formally analyze the possibility of using fixed taxes to increase efficiency, we explore the set of constrained contributions which improve upon the Nash bargaining solution.

The structure of the game we analyze in this section varies from the previous analysis in that the relevant choice variables are $x_{a}$ and $x_{b}$, chosen ex-ante, taking into account that the allocation of funds is determined by ex-post bargaining. Therefore, for this subsection we define $g_{i}$ as a function of $x_{i}$ and $x_{j}$, where $g_{i}\left(x_{i}, x_{j}\right)$ is the bargaining solution in the allocation stage. To facilitate the comparison between unstructured bargaining and partial commitment, we refer to the analogous contributions under the full Nash bargaining solution as $x_{i}^{N B}$. 
Formally, the constrained problem is:

$$
\begin{aligned}
\max _{\left\{x_{a}, x_{b}\right\}} S_{a}+ & S_{b} \\
\text { s.t. } \quad & X=x_{a}+x_{b} \\
\frac{v_{a}^{\prime}}{v_{b}^{\prime}} & =\frac{\left(1-\alpha_{a}\right)}{\left(1-\alpha_{b}\right)} \frac{S_{a}}{S_{b}},
\end{aligned}
$$

where constraint (36) represents the ex-post bargaining solution over allocations. We substitute constraint (35) to reduce the problem to analyzing $x_{a}$ only. This maximization problem need not be concave, since $g_{a}\left(x_{a}\right)$ is not generally "wellbehaved." Since $g_{a}\left(x_{a}\right)$ is continuous and smooth, however, we can still use the first order conditions to characterize all maxima.

The first order conditions give us the following expression:

$$
u_{a}^{\prime}-u_{b}^{\prime}=\left[\left(1-\alpha_{b}\right) v_{a}^{\prime}-\left(1-\alpha_{a}\right) v_{b}^{\prime}\right] \frac{\partial g_{a}}{\partial x_{a}},
$$

which states that the marginal cost of distorting budgetary efficiency is equal to the marginal benefit of moving toward the optimal allocation (or vice versa) at any maximum.

In comparison, note that Nash bargaining equates the ratios of the marginal returns:

$$
\frac{u_{a}^{\prime}}{u_{b}^{\prime}}=\frac{\left(1-\alpha_{b}\right) v_{a}^{\prime}}{\left(1-\alpha_{a}\right) v_{b}^{\prime}}
$$

Since equation (37) does not follow from (38), the Nash bargaining solution will not be generically equal to the constrained efficient solution.

While we cannot characterize the global maximum, we can still analyze whether partial commitment improves over the Nash bargaining solution in a neighborhood of $x_{a}^{N B}$. Note that the Nash bargaining solution can only distort the efficiency margins in one of two ways: either $x_{a}^{N B}<x_{a}^{*}$ and $g_{a}^{N B}>g_{a}^{*}$, or $x_{a}^{N B}>x_{a}^{*}$ and $g_{a}^{N B}<g_{a}^{*}$. Since $\frac{\partial g_{a}}{\partial x_{a}}$ is positive, as $x_{a}$ moves away from $x_{a}^{N B}$ one efficiency margin will move towards parity, while the other will move away from parity. That is, when setting contributions, countries will choose to either improve allocative efficiency or improve budgetary efficiency, since improving one efficiency margin necessarily denigrates the other.

The following proposition characterizes which motivation is prioritized at the Nash bargaining solution: raising funds efficiently or allocating funds efficiently.

\section{Proposition 9}

At the Nash bargaining solution $\left(x^{N B}\right)$ the distortion of budgetary efficiency outweighs the distortion of allocative efficiency. That is,

$$
\left|u_{a}^{\prime}-u_{b}^{\prime}\right| \geq\left|\left(1-\alpha_{b}\right) v_{a}^{\prime}-\left(1-\alpha_{a}\right) v_{b}^{\prime}\right| \frac{\partial g_{a}}{\partial x_{a}} .
$$


Proof: See Appendix E.1.

Somewhat surprisingly, Proposition 9 shows that countries will always set contributions to target the distortion of the budget margin. That is, even in the case where incomes are comparable and the asymmetry in project spillovers is high, the distortion on the budget margin is higher than the distortion on the allocation margin. Additionally, if the maximization problem is concave, the result holds globally and Proposition 9 implies that, relative to the Nash bargaining solution, countries always set contributions ex-ante to improve the distortion of the budget margin. ${ }^{19}$

This section shows that instituting an ex-ante policy designed to increase budgetary efficiency is always weakly optimal, despite increasing the distortion of the allocation.

\subsection{Majority Rule and Legislative Bargaining}

In this subsection, we consider partial commitment in the form of ex-ante implementation of a majority rule, where nations agree on the size of the required majority, $q$, in stage zero. We use a simple model of legislative bargaining similar to Harstad (2005): A formateur first forms a minimum winning coalition of $q$ nations, where $q$ is the number of nations needed to pass legislation, and the coalition then bargains over the allocation of the budget, subject to the participation constraints of the minority. For simplicity, we assume contributions are determined exogenously. ${ }^{20}$ The results we present hold independent of the identity of the formateur, therefore we remain agnostic about the specific procedure used to select the formateur.

When the required size of a winning coalition is equal to $n$, this setup is identical to the Nash bargaining model. When the required size of a winning coalition is smaller than $n$, the legislative bargaining model differs from the previous analysis in two respects: One, the majority coalition bargains over the allocation of both their contributions and the contributions of the minority, and two, the composition of the set of nations that bargain over the utility surplus is endogenous.

As illustrated in section 4, the inefficiency of Nash bargaining stems from the link it produces between contributions and allocations. Majority rule can break this link, at least for the countries in the minority. Therefore, majority rule can improve efficiency, but only if the "right" countries are endogenously chosen to form the majority. The formateur, however, will chose the majority coalition which maximizes their utility, with no regard for efficiency. Therefore, we first identify when the formateur will select countries with high spillover projects to the majority coalition.

${ }^{19}$ To see how this result obtains, take $A$ to be the set of $x_{a}$ that increase aggregate utility over the Nash bargaining solution; $A=\left\{x_{a}: S_{a}\left(x_{a}\right)+S_{b}\left(x_{b}\right)>S_{a}\left(x_{a}^{N B}\right)+S_{b}\left(x_{b}^{N B}\right)\right\}$. If the maximization problem is concave, then $A$ is an interval and $x_{a}^{N B}$ is equal to either the sup or inf of $A$. Therefore, the location of the set $A$ can be characterized by considering the marginal effect of changing $x_{a}$ on aggregate utility at the Nash bargaining solution $\left(x_{a}^{N B}\right)$.

${ }^{20}$ The results are similar if contributions are determined by majority rule. However, in this case the minority is always fully expropriated (they receive their outside option). 


\section{Lemma 2 (Legislative Bargaining)}

Take $i, j$ with $\alpha_{i}>\alpha_{j}$. There exists a $\underline{x} \geq 0$ such that the formateur prefers the majority coalition including $i$ to the majority coalition including $j$ if and only if $x_{j}-x_{i}>\underline{x}$.

\section{Proof: See Appendix E.2.}

By Lemma 2 it is clear that the formateur will not generally choose the majority coalition that consists of the countries with the highest spillover projects. However, Lemma 2 does suggest that the formateur might prefer a majority coalition which contains high-spillover countries in the empirically relevant case where spillovers and contributions are negatively correlated (i.e. when the high spillover nations have low outside options). To explore this possibility further, we consider the following example:

Example: Assume nations are one of two types $\left\{y_{l}, \alpha_{l}\right\}$ or $\left\{y_{h}, \alpha_{h}\right\}$, with $y_{l}<y_{h}$ and $\alpha_{l}>\alpha_{h} . n_{l}$ nations have low incomes and $n_{h}$ nations have high income. In this setting, Lemma 2 translates to the following result, which specifies when the high spillover countries will be chosen to the majority coalition:

\section{Lemma 3}

If $X$ is greater than some $\underline{X}$ and smaller than some $\bar{X}$, then the set of $\left\{x_{l}, x_{h}\right\}$ for which the formateur will choose type $l$ nations for the majority coalition is nonempty.

\section{Proof: See Appendix E.3.}

Lemma 3 allows us to specify some simple situations when majority rule is more efficient than Nash bargaining. For example, a majority rule of $q=n_{l}$ is more efficient than Nash bargaining for any parameter set such that the budget and contributions at the Nash bargaining solution satisfy the conditions of Lemma 3 and efficiency prescribes a corner solution (i.e. allocative efficiency implies no funding for $g_{h}$ ).

By construction, this gives the following proposition:

\section{Proposition 10}

The Nash bargaining solution is not generically more efficient than Majority Rule.

Proposition 10 illustrates that there are non-trivial subsets of the parameter space where adopting a majority rule can improve efficiency. ${ }^{21}$ We cannot, however, claim that legislative bargaining is more efficient than Nash bargaining in any general sense.

The reason for this is twofold: First, a necessary condition for legislative bargaining to be efficient is that the highest spillover nations are chosen to the majority coalition. As Lemma 2 and Lemma 3 demonstrate, this is not always the case, and

\footnotetext{
${ }^{21}$ Proposition 10 is defined for a single union profile, but can be extended to a more general ex-ante
} distribution of $\left\{\left(y_{i}, \alpha_{i}\right)\right\}$. 
will fail if high spillover countries also supply a relatively large proportion of the union budget. Second, since legislative bargaining allocates no funding to countries outside of the majority coalition, it must also be the case that it is relatively efficient to not fund the low spillover projects. While this is not true generally, as illustrated in the discussion of union size (Proposition 4), it will be true for large unions.

\section{Discussion: EU Fiscal Spending as an Example}

A prime justification for centralizing policies at the supranational level under the framework of the European Union is that centralization allows member countries to access benefits of scale and coordination not available to each nation individually. As evidenced by the expansion of funds controlled by the EU under the auspices of the European Stability Mechanism, and by arguments that member nations would benefit from an expansion of growth measures at the EU level, certain benefits from coordination can only be obtained though centralization of fiscal spending at the supranational level. But while benefits from centralization may exist, our analysis shows that there is an inherent efficiency loss due to the autarkic nature of supranational governance and budget negotiations that follow.

In this paper we have analyzed more generally whether a union of sovereign nations can efficiently raise a centralized budget, and then efficiently allocate that budget over a set of joint public good projects. A key element in our analysis is that nations retain the outside option of exiting the union and consuming their contribution to the budget. This leads to the distribution of bargaining power being endogenous to individual contributions to the budget and produces a link between contributions to and allocation of a joint budget that was previously unexplored.

We find that through this channel, unstructured bargaining generically prevents both budgetary and allocative efficiency. However, if the potential members of the union are homogeneous with respect to their income and the social usefulness of the projects they propose to be implemented in the union, then the budget is raised and allocated efficiently. Moreover, efficiency is achieved if the union budget is small relative to domestic consumption and member countries have similar incomes. As the asymmetries between member countries or the importance of the union relative to domestic consumption grows, Nash bargaining leads to increasingly inefficient outcomes.

This has troubling implications for the EU, as income asymmetry has increased due to recent rounds of expansion. Counterbalancing this result, however, is our finding that as the EU expands, the relative bargaining power of nations with high-spillover projects will increase: While EU fiscal spending is by no means fully efficient, an increasing proportion of the budget is allocated to low-income nations, where spillovers from public goods spending are likely to be relatively high.

Relatedly, a larger and more asymmetric EU has resulted in spending at the supranational level that is increasingly redistributive. Perhaps due to this increase, a 
dividing argument in the current debate over expanding fiscal spending at the union level in the EU centers around the redistributive nature of such activity. We do find that redistribution is sustainable even though the bargaining nations are purely selfinterested. It is precisely because of the link between contributions and bargaining power that countries may agree to be net-contributors to the union budget.

The level of redistribution inherent in the Nash bargaining solution depends crucially on the overall size of the budget the union intends to raise. We show that when there is a negative correlation between national income and spillovers from a country's preferred project (a scenario that fits most closely with EU reality) a budget can be picked such that inequality in terms of total utility between member nations is decreased compared to autarky. Such an outcome necessarily implies that the net-gain from joining the union for high-income nations is lower (albeit still positive) than for low-income members. However, this in turn has consequences for the endogenous distribution of bargaining power: Richer nations are able to assert more power and receive an inefficient amount of funding for their own preferred projects. This trade-off between equality and efficiency implies that full redistribution is not necessarily socially desirable.

Lastly, we show that the EU might benefit from enforcing rules specifying contributions as a function of national income (such rules exist, but as we discuss in the introduction, are easily and often circumvented) and a majority rule over allocations of the budget. We find that an exogenous tax rule may indeed improve overall efficiency when compared to a fully unstructured bargaining process. Specifically, such a rule improves efficiency on the contribution margin, forcing wealthier members to pay more. At the same time, however, when countries with high incomes are also the ones proposing the projects with the lowest social returns, this will necessarily decrease the efficiency of the allocation of funds. We show that the efficiency-equality trade-off inherent in the unstructured bargaining outcome will always distort the equity (budget) margin relatively more than the efficiency (allocation) margin. Therefore, an exogenous tax rule that shifts contributions away from the bargaining outcome and towards the efficient contributions will improve overall efficiency.

As the EU has expanded from the original six nations to the current 27, there has been a concurrent evolution of decision making rules. Specifically, the EU has transitioned from unanimity to a qualified majority rule in many areas of competency. We show that majority rule over fiscal spending can improve efficiency as long as the nations with high spillover projects are endogenously selected into the majority coalition. For the main fiscal activities of the EU, the CAP and structural funds, our analysis suggests that a majority decision rule could improve efficiency as long the contributions to the budget by low income members are also relatively low.

It is important to note, however, that Nash bargaining is an "absorbing state" after the constitution stage, in the sense that it is ex-post Pareto efficient and member nations will therefore never unanimously approve a switch to an alternative institution. This suggests an explanation for why unanimity rule persists in the area of EU fiscal spending, even when many other decisions have transitioned to Ordinary 
Legislative Procedure (a qualified majority rule). Therefore, the discussion of alternative institutions is particularly relevant when considering new institutions that increase fiscal spending at the union level, such as the proposed EU growth pact. That is, if unstructured bargaining is used initially, even though a majority rule is preferable and implementable relative to the status quo, the opportunity for the EU to adopt a more efficient institution is lost.

The results of our model are remarkably suggestive of the reality of fiscal spending mechanisms of the European Union today. The explored link between contributing to the union budget and the resulting allocation through the endogenous distribution of bargaining power offers a new explanation as to why unstructured bargaining generally leads to inefficient outcomes and why redistribution in a union is sustainable even though participation is voluntary. Because of the simplicity of the model, we are able to highlight the trade-offs involved when employing an unstructured bargaining process between self-interested sovereign nations, and to scout out scenarios under which more structured institutions are likely to improve welfare.

Our setup allows another interesting route of research: studying the effect of centralized fiscal budgets on the incentives for union enlargement. Given a current set of member states and their composition in terms of income asymmetries, who would benefit most from adding an additional member? What are the effects of adding, for example, a small country to a union of otherwise fairly homogeneous members? Do certain institutional rules of decision making leave more room for strategic enlargements, and how can such rules be designed to share the generated surplus efficiently? The results from this ongoing work will provide further insights into current policy debates in the EU and other supranational unions.

\section{References}

Aghion, Philippe and Patrick Bolton (2003), "Incomplete social contracts." Journal of the European Economic Association, 1, 38-67.

Alesina, Alberto, Ignazio Angeloni, and Federico Etro (2005), "International Unions." The American Economic Review, 95, 602-615.

Barbera, Salvador and Matthew O Jackson (2006), "On the Weights of Nations: Assigning Voting Weights in a Heterogeneous Union." Journal of Political Economy, $114,317-339$.

Besley, Timothy and Stephen Coate (2003), "Centralized versus decentralized provision of local public goods: a political economy approach." Journal of Public Economics, 87, 2611-2637.

Bodenstein, Thilo and Achim Kemmerling (2011), "Ripples in a Rising Tide: Why Some EU Regions Receive More Structural Funds than Others." European Integration Online Papers, 16, 1-24. 
Carrubba, Clifford (1997), "Net Financial Transfers in the European Union: Who Gets What and Why?" Journal of Politics, 59, 469-496.

Conley, John P. and Simon Wilkie (1996), "An extension of the Nash bargaining solution to nonconvex problems." Games and Economic Behavior, 13, 26-38.

Dellmuth, Lisa Maria and Michael F Stoffel (2012), "Distributive politics and intergovernmental transfers: The local allocation of European Union structural funds." European Union Politics, 13, 413-433.

Grossman, Sanford and Oliver Hart (1986), "The Costs and Benefits of Ownership: A Theory of Vertical and Lateral Integration." The Journal of Political Economy, 94, 691-719.

Harstad, Bård (2005), "Majority Rules and Incentives." The Quarterly Journal of Economics, 120, 1535-1568.

Harstad, Bård (2007), "Harmonization and side payments in political cooperation." The American Economic Review, 97, 871-889.

Herrero, Maria Jose (1989), "The Nash Program: Non-convex Bargaining Problems." Journal of Economic Theory, 49, 266-277.

Lockwood, Ben (2002), "Distributive Politics and the Costs of Centralization." The Review of Economic Studies, 69, 313-337.

Maggi, Giovanni and Massimo Morelli (2006), "Self-enforcing voting in international organizations." American Economic Review, 96, 1137-1157.

Nash Jr, John (1950), "The bargaining problem." Econometrica: Journal of the Econometric Society, 18, 155-162.

Oates, Wallace E (1972), "Fiscal Federalism." Harcourt-Brace, New York.

Zhou, Lin (1997), "The Nash bargaining theory with non-convex problems." Econometrica, 65, 681-685.

\section{Appendix}

\section{A Discussion of the Efficiency Benchmark}

In this appendix, we discuss our choice of the efficiency benchmark in more detail. A few of its characteristics have been chosen to ease exposition, possibly at the expense of direct applicability to reality. We discuss these assumptions here to convince the reader that our results hold also when we relax them. We suggest to read sections 4 and 5 before this appendix, as we refer to results derived there. 


\section{A.1 Binding Participation Constraints}

Since we are analyzing a setup without a social planner who can dictate an allocation, nations will only join a union if it is individually rational (IR) for them to do so. They always have the outside option of simply consuming their endowment. Imposing these constraints

$$
u\left(c_{i}\right)+v\left(g_{i}+\sum_{j \neq i} \alpha_{j} g_{j}\right) \geq u\left(y_{i}\right) \quad \forall i
$$

in the problem above, one might argue, yields a more relevant efficiency benchmark.

Given this complication, the efficiency benchmarks would have to be derived from the general problem (7) through (12) with the addition of the set of IR constraints. This, as we will see below, would simply yield an additional condition in each definition of efficiency benchmarks for the case that a participation constraint binds. We consider it unnecessary to keep track of the additional special case. If a participation constraint would bind at the efficient solution, the modified efficiency benchmark would change to just accommodate that. The Nash bargaining process, however, generally leaves all countries strictly better off, so that none of the IR constraints binds, so the Nash bargaining solution would be inefficient beyond what is called for by the binding IR constraint - all our results remain unchanged. Only the distance to efficiency in our numerical solutions might be smaller whenever an IR constraint would be violated at the benchmark.

For the sake of completeness, we show here how even one binding IR constraint distorts both budgetary and allocative efficiency. The resulting allocation would generally be a trade-off between decreasing the union budget and a distorted allocation of funds so that individual rationality is guaranteed. This trade-off is not trivial, and crucially depends on the functional form of preferences. Therefore we judge it to be impractical as a benchmark.

Suppose only one participation constraint, that of country $k$, binds at the first-best allocation. The first order conditions to this problem then are:

$$
\begin{aligned}
u_{i}^{\prime} & =\lambda \quad \forall i \neq k \\
u_{k}^{\prime}(1+\mu) & =\lambda \\
v_{i}^{\prime}+\alpha_{i} \sum_{j \neq i} v_{j}^{\prime} & =\lambda \quad \forall i \neq k \\
v_{k}^{\prime}(1+\mu)+\alpha_{k} \sum_{j \neq k} v_{j}^{\prime} & =\lambda
\end{aligned}
$$

Since only one IR constraint binds, only one associated Lagrange multiplier is nonzero and enters the optimality conditions. Notice though that even this one additional constraint is enough to distort budgetary efficiency:

$$
u_{k}^{\prime}=\frac{1}{1+\mu} u_{i}^{\prime}
$$


as well as allocative efficiency:

$$
v_{k}^{\prime}(1+\mu)+\alpha_{k} \sum_{j \neq k} v_{j}^{\prime}=v_{i}^{\prime}+\alpha_{i} \sum_{j \neq i} v_{j}^{\prime}
$$

Here the one binding participation constraint distorts the allocation in order to satisfy individual rationality.

\section{A.2 Binding No-transfers and Technology Constraints}

Unlike the IR constraints, we do consider the no-transfer constraints (11) as well as the technological constraints (12) important when defining a practicable benchmark. They are the source for corners both in the efficient allocation and the Nash bargaining solution. It is important to note that a binding no-transfer constraint will only cause a corner in contributions, while it is the technology constraint $g_{i} \geq 0$ that causes corners in allocations. We demonstrate the former here, the later follows trivially.

The first-best allocation, denoted with superscript $F B$ is a solution to the following planning problem:

$$
\begin{aligned}
\max _{\left\{c_{i}, g_{i}\right\}_{i=1, \ldots, n}} & \sum_{i=1}^{n} u\left(c_{i}\right)+v\left(g_{i}+\sum_{j \neq i} \alpha_{j} g_{j}\right) \\
\text { s.t. } \quad & c_{i}+x_{i} \leq y_{i} \quad \forall i \\
& \sum_{i} g_{i} \leq \sum_{i} x_{i} \\
& x_{i} \geq 0 \quad \forall i
\end{aligned}
$$

The first order conditions with respect to domestic consumption, contributions to the union budget, and union projects are respectively:

$$
\begin{aligned}
u^{\prime}\left(c_{i}\right) & =\lambda_{i} \quad \forall i \\
\lambda_{i} & =\mu \quad \forall i \\
v_{i}^{\prime}+\alpha_{i} \sum_{j \neq i} v_{j}^{\prime} & =\mu \quad \forall i, j
\end{aligned}
$$

where $\lambda_{i}$ and $\mu$ are the Lagrange multipliers associated with the individual budget constraints (48) and the union wide budget constraint (49) respectively. However, these conditions describe only interior solutions, i.e. are met only when constraints (50) are slack. Suppose one of these constraints is violated at the fully efficient firstbest allocation, i.e. $y_{i}<c^{F B}$ for one country $i$. There is no choice but to implement a corner solution with $x_{i}=0$ and $c_{i}=y_{i}<c_{j}=c^{F B}$. Notice however, that it will not distort allocative efficiency as a result. How a given budget is allocated 
between projects is entirely prescribed by conditions (53), which do not depend on the individual Lagrange multipliers $\lambda_{i}$. Allocative efficiency (II) is never distorted at the first-best allocation. Only budgetary efficiency (I) is distorted such that

$$
u_{j}^{\prime}=v_{j}^{\prime}+\alpha_{j} \sum_{k \neq j} v_{k}^{\prime}=v_{i}^{\prime}+\alpha_{i} \sum_{k \neq i} v_{k}^{\prime}<u_{i}^{\prime}
$$

From this analysis it is obvious to see that without preference separability between domestic consumption and union consumption, conditions (53) will generally depend on all $\lambda_{i}$, so that also allocative efficiency would be distorted. Intuitively, the allocation might be such that it indirectly transfers utility toward poor countries, since direct transfers are not allowed. We abstract from this channel.

\section{A.3 Endogenous Budget}

We have taken the overall size of the union's budget $X$ as pre-determined, and only focus on the two aspects of efficiency that do not relate to a redistributive motive. From the definition of social efficiency (III) it should be clear, however, that the socially efficient allocation also requires budgetary and allocative efficiency. Thus, all our results hold true even if the budget $X$ is chosen endogenously.

In fact, we can add the result that the Nash bargaining solution achieves also the efficient total budget in the cases of symmetry and quasi-linear preferences, but not generically (proofs are analogous to the corresponding ones with a fixed budget, found in Appendix C).

\section{B Nash Bargaining over Non-Convex Sets}

The Nash bargaining Problem asks how individuals "who have the opportunity to collaborate for mutual benefit" (Nash Jr (1950)) divide the utility gained through collaboration. Nash Jr (1950) proved that there exists a unique solution to this problem that is: independent of the cardinality of the utility functions, gives a Pareto optimal outcome, symmetric, and independent of irrelevant alternatives. Moreover, he shows that the bargaining solution maximizes the product of the individual utility surpluses from cooperation: this division of utilities is know as the Nash bargaining Solution.

Nash's original proof of the Nash bargaining Solution was limited to bargaining over a convex set of utility outcomes, $S$. A set of papers extend the Nash bargaining (NB) Problem to non-convex sets by imposing alternative axioms (Herrero (1989), Conley and Wilkie (1996), Zhou (1997)). This appendix takes an alternative approach: we show that the NB solution holds on a relevant set of non-convex sets utility outcomes. Specifically, we weaken the convexity constraint in Nash's seminal paper to the following: 
Convexity Constraint: The convex hull of the set of Pareto outcomes is in $S$.

The following Theorem shows that Nash's standard bargaining solution holds on this more general set of utility outcomes.

\section{Theorem 1}

There exists a unique set of utilities, $\left\{u_{1}^{*}, u_{2}^{*}\right\}$, that satisfy the Nash bargaining axioms. Moreover, $\left\{u_{1}^{*}, u_{2}^{*}\right\}$ is the unique maximum of $u_{1} u_{2}$.

Proof: Since $S$ is compact there exists a $\left\{\hat{u}_{1}, \hat{u_{2}}\right\}$ in $S$ that maximizes $u_{1} u_{2}$. Without loss of generality, we renormalize $\left\{\hat{u}_{1}, \hat{u_{2}}\right\}$ to $\{1,1\}$. In Nash's original setup, where $S$ is convex, two results would trivially follow:

Claim 1: $\left\{\hat{u_{1}}, \hat{u_{2}}\right\}$ is the unique maximum of $u_{1} u_{2}$ in $S$.

Claim 2: There does not exist $\left\{u_{1}^{\prime}, u_{2}^{\prime}\right\}$ in $S$ such that $u_{1}^{\prime}+u_{2}^{\prime}>2$.

Here we prove that claim 1 and claim 2 still hold given our weakened convexity constraint. We start with claim 2.

Proof of claim 2: First, we show that $\{1,1\}$ is in the set of Pareto outcomes, which we label $P$. By contradiction, if $\{1,1\}$ is not in $P$, then there is a point in $S$, $\left\{\check{u_{1}}, \check{u_{2}}\right\}$ with $\check{u_{1}}, \check{u_{2}} \geq 1$, and either $\check{u_{1}}>1$ or $\check{u_{2}}>1$. Since $\check{u_{1}} \check{u_{2}}>1,\{1,1\}$ does not maximize $u_{1} u_{2}$.

Next, note that if there exists a $\left\{u_{1}^{\prime}, u_{2}^{\prime}\right\}$ in $S$ such that $u_{1}^{\prime}+u_{2}^{\prime}>2$, then there also exists $\left\{u_{1}^{\prime \prime}, u_{2}^{\prime \prime}\right\}$ such that $u_{1}^{\prime \prime}+u_{2}^{\prime \prime}>2$ and $\left\{u_{1}^{\prime \prime}, u_{2}^{\prime \prime}\right\} \in P$ : if $\left\{u_{1}^{\prime}, u_{2}^{\prime}\right\} \notin P$, then there exists some exists $\left\{u_{1}^{\prime \prime}, u_{2}^{\prime \prime}\right\} \in P$ such that $u_{1}^{\prime \prime}+u_{2}^{\prime \prime}>u_{1}^{\prime}+u_{2}^{\prime}>2$. Lastly, since $u_{1}^{\prime \prime}+u_{2}^{\prime \prime}>2$ there is a convex combination of $\left\{u_{1}^{\prime \prime}, u_{2}^{\prime \prime}\right\}$ and $\{1,1\}$ such that $u_{1} u_{2}>1$. And since $\left\{u_{1}^{\prime \prime}, u_{2}^{\prime \prime}\right\}$ and $\{1,1\}$ are both in $P$, and the convex hull of $P$ is in $S$, this convex combination is also in $S$, which contradicts the fact that $\{1,1\}$ maximizes $u_{1} u_{2}$.

Proof of claim 1: Assume $\left\{u_{1}^{\prime}, u_{2}^{\prime}\right\}$ maximizes $u_{1} u_{2}$ on $S$, i.e. $u_{1}^{\prime} u_{2}^{\prime}=1$. Claim 2 shows that $u_{1}^{\prime}+u_{2}^{\prime} \leq 2$. Substituting in for $u_{2}^{\prime}$ gives $u_{1}^{\prime}+\frac{1}{u_{1}^{\prime}} \leq 2$, which, after some algebra, gives $\left(u_{1}^{\prime}-1\right)^{2} \leq 0$. This equation is only satisfied when $u_{1}^{\prime}=1$, which in turn implies that $u_{2}^{\prime}=1$.

This completes the proof; given Claim 1 and Claim 2 the result follows from Nash's original proof.

Theorem 1 gives the following result, which proves that the Nash bargaining model hold in our model. 


\section{Corollary 2}

The Nash bargaining Solution maximizes:

$$
\begin{aligned}
\max _{\left\{x_{i}, g_{i}\right\}_{i=1, \ldots, n}} & \prod_{i=1}^{n}\left[u\left(y_{i}-x_{i}\right)+v\left(g_{i}+\sum_{j \neq i} \alpha_{j} g_{j}\right)-u\left(y_{i}\right)\right] \\
\text { s.t. } & \sum_{i} g_{i}=\sum_{i} x_{i}
\end{aligned}
$$

Proof: The Pareto set is the set of $g_{i}$ 's such that $\sum_{i} g_{i}=\sum_{i} x_{i}$. Since $v(\cdot)$ is concave and $\partial v\left(g_{i}+\sum_{j \neq i} \alpha_{j} g_{j}\right) / \partial g_{i}>\partial v\left(g_{i}+\sum_{j \neq i} \alpha_{j} g_{j}\right) / \partial g_{j}$ for any combination of $g_{i}$ 's and for all $j \neq i$, the convex set of the Pareto set is contained within the set of utility outcomes that are achievable with budget $\sum_{i} x_{i}$.

\section{Proofs of all results in section 4}

We present all propositions and their proofs for the general case of $n$ countries. The Nash bargaining solution for general $n$ is characterized by:

$$
\begin{aligned}
\frac{u_{i}^{\prime}}{u_{j}^{\prime}} & =\frac{S_{i}}{S_{j}} & \forall i, j \\
v_{i}^{\prime}\left(1-\alpha_{j}\right) & =v_{j}^{\prime}\left(1-\alpha_{i}\right) \frac{S_{i}}{S_{j}}-\left(\alpha_{i}-\alpha_{j}\right) \sum_{k \neq i, j} v_{k}^{\prime} \frac{S_{i}}{S_{k}} & \forall i, j \\
\sum_{i=1} g_{i} & =X & \\
\sum_{i=1} x_{i} & =X &
\end{aligned}
$$

where again $S_{i}=u\left(y_{i}-x_{i}\right)+v_{i}-u\left(y_{i}\right)$ denotes the surplus generated for country $i=1, \ldots, n$ respectively.

\section{C.1 Symmetry (Proposition 1)}

\section{Proposition 11}

If countries are perfectly symmetric, i.e. $y_{i}=y_{j}$ and $\alpha_{i}=\alpha_{j}$ for all $i, j$, then, for any intended budget $X$, the Nash bargaining solution coincides with the efficient allocation.

In case all $n$ nations are perfectly symmetric, the definitions (I) and (II) imply efficient contributions and allocations $x_{i}=x_{j}=x$ and $g_{i}=g_{j}=g$ for all $i, j$, which exactly achieves $S_{i}=S_{j}$ for all $i, j$.

Then the equations in definition (I) and definition (II) are the same as 57 through 60 characterizing the Nash bargaining solution, so that the allocations are identical. 


\section{C.2 Quasi-linear preferences (Proposition 2)}

\section{Proposition 12}

If preferences are quasi-linear in domestic consumption, i.e. $U_{i}=c_{i}+v\left(g_{i}+\alpha_{j} g_{j}\right)$, then, for any intended budget $X$, the bargaining solution coincides with one efficient allocation.

With quasi-linear preferences, condition 57 reduces to $S_{i}=S_{j}$ for all $i, j$, so that in turn conditions 58 through 60 exactly coincide with the efficiency conditions in definitions (I) and (II).

\section{C.3 Corners (Lemma 1)}

We simply proof this lemma by example. Suppose preferences are

$$
U_{i}=\log \left(c_{i}\right)+\log \left(g_{i}+\alpha_{j} g_{j}\right) \quad i=a, b
$$

and parameters $y_{a}=10, y_{b}=5, X=2, \alpha_{a}=0.9$, and $\alpha_{b}=0.1$. Then, both the efficient allocation and the Nash bargaining solution specify $x_{a}=2, x_{b}=0, g_{a}=2$, and $g_{b}=0$. Examples with just a corner in contributions or allocations can be constructed similarly.

\section{C.4 Generic inefficiency (Proposition 3)}

Suppose that $u(\cdot)$ is strictly concave and that parameters are such that the solution is not a "double corner".

\section{Proposition 13}

Generically, the efficient allocation cannot be supported as a Nash bargaining solution.

Suppose the bargaining solution was efficient. Comparing equilibrium conditions (57) through (60) to the optimality conditions of the definitions (I) and (II) shows that the Nash bargaining solution is efficient if and only if the surpluses are exactly equal, i.e. $S_{i}=S_{j}$ for all countries. However, the efficient allocation implies $S_{i} \neq S_{j}$ almost always, which in turn implies that the bargaining solution is not efficient. We arrive at a contradiction. Exceptions may arise under specific combination of parameters where the efficient solution by coincidence exactly yields $S_{i}=S_{j}$. In any of these cases, changing any one of the parameters by $\epsilon \neq 0$ will again lead to $S_{a} \neq S_{b}$ and so to the Nash bargaining solution to not be efficient. 


\section{C.5 Proof of Corollary 1}

\section{Corollary 3}

When the Nash bargaining outcome does not coincide with the efficient allocation, it distorts both budgetary and allocative efficiency.

Proof: If $S_{i} \neq S_{j}$ for all $i, j$, then both budgetary efficiency and allocative efficiency are not satisfied.

\section{C.6 Proof of Proposition 4}

The proof follows from the fact that, for a union large enough, both the efficiency condition and the Nash bargaining result specify that the whole budget be allocated to the project with the highest spillovers.

First, note that in the allocative efficiency condition (definition (II)),

$$
v_{i}^{\prime}\left(1-\alpha_{j}\right)=v_{j}^{\prime}\left(1-\alpha_{i}\right)-\left(\alpha_{i}-\alpha_{j}\right) \sum_{k \neq i, j} v_{k}^{\prime} \forall i, j
$$

the term $\sum_{k \neq i, j} v_{k}^{\prime}$ is strictly increasing in $n$, and $g_{i}$ is increasing in $\sum_{k \neq i, j} v_{k}^{\prime}$ if $\alpha_{i}>\alpha_{j}$. Therefore, for an $n$ large enough, allocative efficiency will require that $g_{m}=X$ for country $m$ s.t. $\alpha_{m}=\max \left\{\alpha_{i}\right\}_{n}$.

The same logic holds for the Nash bargaining solution:

$$
v_{i}^{\prime}\left(1-\alpha_{j}\right) \frac{S_{j}}{S_{i}}=v_{j}^{\prime}\left(1-\alpha_{i}\right)-\left(\alpha_{i}-\alpha_{j}\right) \sum_{k \neq i, j} v_{k}^{\prime} \frac{S_{i}}{S_{k}} \quad \forall i, j
$$

\section{C.7 Asymmetric spillovers: Description of the numerical experiment in section 4.2}

We perform an exercise on increasing asymmetry. However, simply changing the spillovers $\alpha_{i}$ changes also the efficient solutions, and so hinders the comparison between welfare achieved by bargaining to the efficient outcome. Therefore we use the following routine to pick parameter combinations with increasing asymmetry, but constant efficient aggregate welfare.

Take $\alpha_{a}=\alpha$ and $\alpha_{b}=\alpha+z$. Fixing contributions at the efficient level (not influenced by $\alpha$, only a function of incomes), take $W(\alpha)=\max _{g_{a}, g_{b}}\left(U_{a}+U_{b}\right)$; i.e. the efficient level of aggregate utility. Trivially, $W(\alpha)$ is strictly increasing in $\alpha$, since aggregate utility increases as $\alpha$ increases even without re-optimizing $g_{a}$ and $g_{b}$. Therefore, for a given budget and a given $\mathrm{z}$, the $\alpha$ s.t. $W(\alpha)=Q$ (some constant), is unique. 
This implies that, for any increasing sequence $\{z\}$, for a fixed $\mathrm{Q}$ and efficient contributions $\left(x_{a}, x_{b}\right)$, there exists a unique corresponding sequence of $\{\alpha\}$, which we compute. Then, we compute the Nash bargaining solution for the parameters $\{X, \alpha, z\}$ and compare aggregate utility from Nash bargaining to Q.

\section{Proofs of all results in Section 5}

\section{D.1 Proof of Proposition 5}

Consider the Nash bargaining problem 16 through 18 with the additional constraint that there be no redistribution, i.e.

$$
x_{a}-g_{a}=x_{b}-g_{b}
$$

Setting up the Lagrangian and associating Lagrange multiplier $\mu$ to this extra constraint yields

$$
\begin{aligned}
& \mu=\frac{1}{2}\left(u_{b}^{\prime} S_{a}-u_{a}^{\prime} S_{b}\right) \\
& \mu=\frac{1}{2}\left(v_{b}^{\prime}\left(1-\alpha_{a}\right) S_{a}-v_{a}^{\prime}\left(1-\alpha_{b}\right) S_{b}\right)
\end{aligned}
$$

For the multiplier to be zero, the functional forms and parameters would ahve to exactly line up so that both terms on the right hand sides are zero simultaneously exactly at the allocation where $x_{a}=g_{a}$ and $x_{b}=g_{b}$. This can only be true at points with zero mass. Whenever $\mu \neq 0$, the Nash bargaining solution without this constraint would actually violate it, i.e. have $x_{i} \neq g_{i}$.

\section{D.2 Proof of Proposition 6}

This proof proceeds by contradiction. Suppose $y_{a}>y_{b}, \alpha_{a}<\alpha_{b}$, and the Nash bargaining allocation is such that $S_{a}>S_{b}$. Condition (26) then implies that $u\left(c_{a}\right)<$ $u\left(c_{b}\right)$. Moreover, condition (27) implies that $v\left(g_{a}+\alpha_{b} g_{b}\right)<v\left(g_{b}+\alpha_{a} g_{a}\right)$. These two together, however imply:

$$
\begin{aligned}
u\left(c_{a}\right)+v\left(g_{a}+\alpha_{b} g_{b}\right) & <u\left(c_{b}\right) v\left(g_{b}+\alpha_{a} g_{a}\right) \\
u\left(c_{a}\right)+v\left(g_{a}+\alpha_{b} g_{b}\right)-u\left(y_{a}\right) & <u\left(c_{b}\right) v\left(g_{b}+\alpha_{a} g_{a}\right)-u\left(y_{b}\right) \\
S_{a} & <S_{b}
\end{aligned}
$$

We arrive at a contradiction. Thus, at the Nash bargaining solution, when $y_{a}>y_{b}$ and $\alpha_{a}<\alpha_{b}$, it can only be that $S_{a} \leq S_{b}$. 


\section{D.3 Proof of Proposition 7}

From proposition 6 we know that at the Nash bargaining solution, $S_{a}<S_{b}$, which means that $u\left(c_{a}\right)>u\left(c_{b}\right)$. Suppose the budget is very small $X=\epsilon>0$. Then, by the Inada conditions, $v_{i}^{\prime} \sim-\infty$, which means that $v_{a} \approx v_{b}$. Then

$$
\begin{aligned}
& S_{a}<S_{b} \\
& \rightarrow u\left(c_{a}\right)-u\left(c_{b}\right)+v_{a}-v_{b}<u\left(y_{a}\right)-u\left(y_{b}\right) \\
& \rightarrow \quad 0<u\left(c_{a}\right)-u\left(c_{b}\right)<u\left(y_{a}\right)-u\left(y_{b}\right)
\end{aligned}
$$

which is a decrease in inequality in terms of utility.

It should be clear from proposition 6 , however, that inequality could also be reversed: Since the high-income nation always gains less than the low income nation, they could actually change place in the utility ranking.

\section{D.4 Proof of Proposition 8}

From Proposition 6 it is clear that at the Nash bargaining solution, $S_{a} \leq S_{b}$, which means that $x_{a}$ is inefficiently low and $g_{a}$ inefficiently high. Then, all else equal, increasing $x_{a}$ will decrease $S_{a}$ and increase $S_{b}$, giving even more relative bargaining weight to nation $a$, so that the allocation of funds will be tilted even more toward the inefficient project $g_{a}$.

\section{E Proofs of results in Section 6}

\section{E.1 Proof of Proposition 9}

First note that $u_{a}^{\prime}>u_{b}^{\prime}$ implies $\left(1-\alpha_{b}\right) v_{a}^{\prime}>\left(1-\alpha_{a}\right) v_{b}^{\prime}$ by equation 38 . We will complete the proof for the case of $u_{a}^{\prime}>u_{b}^{\prime}$ (the opposite case is analogous), which implies that the desired result is:

$$
u_{a}^{\prime}-u_{b}^{\prime} \geq\left(1-\alpha_{b}\right) v_{a}^{\prime}-\left(1-\alpha_{a}\right) v_{b}^{\prime} \frac{\partial g_{a}}{\partial x_{a}}
$$

Using the Implicit Function Theorem we get:

$$
\frac{\partial g_{a}}{\partial x_{a}}=\frac{v_{a}^{\prime}\left(1-\alpha_{b}\right) u_{b}^{\prime}+v_{b}^{\prime}\left(1-\alpha_{a}\right) u_{a}^{\prime}}{2 v_{a}^{\prime}\left(1-\alpha_{b}\right) v_{b}^{\prime}\left(1-\alpha_{a}\right)-v_{a}^{\prime \prime}\left(1-\alpha_{b}\right)^{2} S_{b}-v_{b}^{\prime \prime}\left(1-\alpha_{a}\right)^{2} S_{a}} \equiv \frac{Q}{Z}
$$

First, we plug in the solution for $\frac{\partial g_{a}}{\partial x_{a}}$ into equation 70 and divide both sides by $u_{a}^{\prime}$ to get:

$$
1-\frac{u_{b}^{\prime}}{u_{a}^{\prime}} \geq\left[\left(1-\alpha_{b}\right) v_{a}^{\prime}-\left(1-\alpha_{a}\right) v_{b}^{\prime}\right]\left[\left(1-\alpha_{b}\right) v_{a}^{\prime} \frac{u_{b}^{\prime}}{u_{a}^{\prime}}+\left(1-\alpha_{a}\right) v_{b}^{\prime}\right] Z^{-1}
$$


We then use equation 38 to get:

$$
1 \geq\left[\left(1-\alpha_{b}\right) v_{a}^{\prime}-\left(1-\alpha_{a}\right) v_{b}^{\prime}\right]\left[2\left(1-\alpha_{a}\right) v_{b}^{\prime}\right] Z^{-1}+\frac{\left(1-\alpha_{a}\right) v_{b}^{\prime}}{\left(1-\alpha_{b}\right) v_{a}^{\prime}} \equiv Y
$$

Since $\left(v_{a}^{\prime \prime}\left(1-\alpha_{b}\right)^{2} S_{b}+v_{b}^{\prime \prime}\left(1-\alpha_{a}\right)^{2} S_{a}\right)$ is non-positive,

$$
Y \leq \frac{\left[\left(1-\alpha_{b}\right) v_{a}^{\prime}-\left(1-\alpha_{a}\right) v_{b}^{\prime}\right]\left[2\left(1-\alpha_{a}\right) v_{b}^{\prime}\right]}{Z+\left(v_{a}^{\prime \prime}\left(1-\alpha_{b}\right)^{2} S_{b}+v_{b}^{\prime \prime}\left(1-\alpha_{a}\right)^{2} S_{a}\right)}+\frac{\left(1-\alpha_{a}\right) v_{b}^{\prime}}{\left(1-\alpha_{b}\right) v_{a}^{\prime}},
$$

which is equivalent to:

$$
Y \leq \frac{\left[\left(1-\alpha_{b}\right) v_{a}^{\prime}-\left(1-\alpha_{a}\right) v_{b}^{\prime}\right]\left[2\left(1-\alpha_{a}\right) v_{b}^{\prime}\right]}{2 v_{a}^{\prime}\left(1-\alpha_{b}\right) v_{b}^{\prime}\left(1-\alpha_{a}\right)}+\frac{\left(1-\alpha_{a}\right) v_{b}^{\prime}}{\left(1-\alpha_{b}\right) v_{a}^{\prime}}
$$

After some algebra, this simplifies to:

$$
Y \leq 1
$$

which gives the desired result.

\section{E.2 Proof of Lemma 2}

The result is complicated by the fact that the the formateur's utility may be nonmonotonic in $\alpha_{j}$. On one hand, the overall surplus of the majority coalition is increasing in $\alpha_{j}$ (income effect). On the other hand, the formateur's share of the surplus is decreasing in $\alpha_{j}$ (substitution effect). Depending upon the specific composition of $\alpha$ 's, the substitution effect can dominate the income effect, in which case, all else equal, the formateur prefers to form a coalition of countries with low spillover projects.

The non-monotonicity of the formateur's utility in $\alpha_{i}$ can always be overcome, however, by the difference in contributions. A higher $x_{j}$ implies a higher outside option, which increases $j$ 's bargaining power and decreases the share of the budget that is allocated to the formateur's project. Formally, Nash bargaining gives:

$$
S_{f}=\frac{u_{f}^{\prime}}{u_{j}^{\prime}} S_{j}
$$

which shows that $S_{f}$ is strictly decreasing in $x_{j}$. Therefore, any decrease in the relative utility surplus of the formateur, due to a higher $\alpha_{i}$, is outweighed by a large enough difference in $x_{j}$ and $x_{i}$.

\section{E.3 Proof of Lemma 3}

Take $d_{i}$ to be the utility value of the outside option; there exists some $\left(d_{h}-d_{l}\right)=\bar{d}$ large enough that the formateur's utility is higher if she includes type $l$ countries in the majority coalition. 
Therefore, the set of $\left\{x_{l}, x_{h}\right\}$ for which the formateur's utility is higher with type $l$ nations in the majority coalition is non-empty as long as there exist $x_{l}, x_{h}$ such that: $\sum_{l} x_{l}+\sum_{h} x_{h}=X$, and $\left(d_{h}-d_{l}\right) \geq \bar{d}$ large enough. Note that this will be satisfied as long as $X$ is large enough that $\left(d_{h}-d_{l}\right)>\bar{d}$ for $x_{l}=0, x_{h}=\frac{X}{n_{h}}$ if $\frac{X}{n_{h}}<y_{h}$, and $X$ is small enough that $\left(d_{h}-d_{l}\right)>\bar{d}$ for $x_{l}=\frac{X-n_{h} y_{h}}{n_{l}}, x_{h}=y_{h}$ if $\frac{X}{n_{h}} \geq y_{h}$. 